\title{
Molecular cloning, mRNA expression and biological activity of the pheromone biosynthesis activating neuropeptide (PBAN) from the European corn borer, Ostrinia nubilalis
}

AQ51 5 J. Fodor, G. Köblös, Á. Kákai, Z. Kárpáti, B. P. Molnár,

6 T. Dankó, G. Bozsik, C. Bognár, G. Szőcs and

A. Fónagy

8 Centre for Agricultural Research, Plant Protection

9 Institute, Hungarian Academy of Sciences, Budapest,

10 Hungary

\section{Abstract}

3 Pheromone biosynthesis activating neuropeptide AQ3 14 (PBAN) is a member of the pyrokinin (FXPRLamide) 15 insect neuropeptides. Here, we report the cloning of

AQ4 16 the gene Ostnu-PBAN from the $E$ and $Z$ pheromone 17 strains of the European corn borer (ECB), Ostrinia 18 nubilalis (Lepidoptera: Crambidae), a major pest of 19 maize. The Ostnu-PBAN genomic sequence is $>5 \mathrm{~kb}$ 20 in length and consists of six exons. The deduced amino acid sequence revealed a 200-residue precur22 sor protein including a signal peptide, a 24-amino AQ5 23 acid (aa) diapause hormone, a 37-aa PBAN and three 24 other FXPRLamide neuropeptides. Our in vivo assays 25 suggest that the 37 -aa synthetic Ostnu-PBAN is 26 hormonally active in the pheromone gland. It restores sex pheromone production to normal levels in mated 8 females and decapitated virgins of both $E$ and $Z$ 9 cultures. The results of a real-time PCR analysis AQ6 30 indicated that Ostnu-PBAN mRNA levels reached a 31 plateau in the brain-suboesophageal ganglion com32 plexes 1 day after eclosion, and mating did not affect 33 the mRNA expression. Three size classes of Ostnu34 PBAN mRNA (1.9, 2.0 and $2.1 \mathrm{~kb})$ were obtained, dif35 fering only in the length of the $3^{\prime}$ untranslated region. 36 However, there was no correlation between sequence

Correspondence: József Fodor, Centre for Agricultural Research, Plant Protection Institute, Hungarian Academy of Sciences; Herman Ottó út 15, H-1022 Budapest, Hungary. Tel.: 13614877520 ; fax: 13614877555 ; divergence and the pheromone composition, voltinism or geographical origin (Hungary, Slovenia, 38 Sweden, Turkey) of ECB moths.

Keywords: Ostrinia nubilalis, lepidopteran pest, 40 pheromone biosynthesis activating neuropeptide, 41 sex pheromone.

Introduction

In many moth species, the female releases a volatile sex 44 pheromone that attracts conspecific males for mating 45 (Tamaki, 1985). Sex pheromones are typically synthesized de novo from acetyl-CoA in the pheromone gland $(P G)$, which is located between the eighth and ninth abdominal segments of females (Percy-Cunningham \& McDonald, 1987). Most moths utilize Type I sex pheromones that are composed of fatty acid derivatives (C10C18 straight chain aldehydes, alcohols or their acetate esters) usually containing double bonds in defined positions and geometric configurations (Bjostad et al., 1987; Ando et al., 2004). The blend ratio of sex pheromone components is species specific, and the structural and compositional variations of the components serve as the basis for mate recognition (Roelofs \& Rooney, 2003). Female moths often exhibit a diel periodicity in pheromone production that is regulated by the pheromone biosynthesis activating neuropeptide (PBAN). The first PBAN was identified from brain-suboesophageal ganglion (SG) complexes of Helicoverpa zea as a 33-amino acid (aa) C-terminal amidated peptide that is released into the haemolymph only during the scotophase (Raina et al., 1989). Subsequently, neuropeptides with similar functionalities and sequence homologies to Helze-PBAN were identified from Bombyx mori (Kitamura et al., 1989) and Lymantria dispar (Masler et al., 1994). Almost simultaneously, a 24-residue peptide with egg diapauseinducing activity was isolated from SG extracts of B. mori (Imai et al., 1991). This work revealed that the 

FGPRLamide C-terminus that is almost identical to those of PBANs and myotropic pyrokinin (PK) insect 6 peptides (Gäde, 1997; Predel \& Nachman, 2006). 77 Structure-activity relationship analyses showed that the 78 highly conserved C-terminal pentapeptide characterized 79 by FXPRLamide or a similar sequence (where $\mathrm{X}$ is a variable amino acid) is the active core region, represent81 ing the minimum number of residues required for physio82 logical activity (Nachman et al., 1986; Raina \& Kempe, B3 1990; Kuniyoshi et al., 1992). The FXPRLamide neuro34 peptides are widely distributed in insects and control 85 diverse physiological processes (reviewed in Predel \& Nachman, 2006; Jurenka \& Nusawardani, 2011; Altstein et al., 2013; Jurenka, 2015). Following purification of the Bommo-DH, Bommo-PBAN and Helze-PBAN neuropeptides, molecular cloning techniques allowed identification of the DH-PBAN gene from B. mori and $\mathrm{H}$. zea (Davis et al., 1992; Kawano et al., 1992; Ma et al., 1994). DNA 2 sequencing revealed that the DH-PBAN gene encodes a 3 larger precursor whose post-translational proteolytic processing yields DH, PBAN and three additional short peptides

96 (a-, b- and g-SG neuropeptides, ie SGNPs), all sharing 97 the common C-terminal $\operatorname{FXP}(\mathrm{R} / \mathrm{K})$ Lamide motif. Since 98 then, cDNAs encoding PK/PBAN neuropeptides sharing 9 an overall conserved structure have been published for 100 more than 20 lepidopteran species (Jurenka, 2015). To 101 date, however, no sequence information has been pro102 vided for the PBAN gene in the European corn borer 103 (ECB), Ostrinia nubilalis Hbn. (Lepidoptera: Crambidae, 104 Pyraustinae), which is an important economic pest of 105 corn, hop, millet and hemp in the Northern Hemisphere 106 (Caffrey \& Worthley, 1927; Dillehay et al., 2005) and a 107 model species for the study of evolutionary changes in 108 sex pheromone communication (Lassance, 2010).

109 ECB populations are characterized by a variation in 110 life history traits, such as voltinism. In Hungary, survey 111 evidence indicates the presence of both univoltine and 112 bivoltine life cycles. Typical bivoltine ECB populations 113 occur in southern regions of the country, whereas univol114 tine populations are found in the north (Mészáros, 1969; 115 Keszthelyi, 2010). Female ECB moths exhibit a diel peri116 odicity in the emission of sex pheromone with peaks in 117 the late scotophase and troughs in the photophase 118 (Foster, 2004; Kárpáti et al., 2007). In the early 1970s 119 two pheromonally distinct but otherwise indistinguishable 120 races of Os. nubilalis were identified both in its native 121 Palearctic range and its introduced range in North Amer-

AQ10 122 ica (Klun \& Cooperators, 1975). The females produce 123 mixtures of (Z)-11- and (E)-11-tetradecenyl acetate 124 (Z11-14:Ac and E11-14:Ac) as their sex pheromone 125 (Klun et al., 1973). The so-called Z-strain is character126 ized by the production and perception of a 97:3 molar ratio of Z11-14:Ac and E11-14:Ac, whereas the E-strain 127 ECB utilizes a 1:99 blend of Z11-/E11-14:Ac (Kochan- 128 sky et al., 1975). Substantial research has been con- 129 ducted to define the genetic basis of pheromone 130 production in Os. nubilalis, and accumulating evidence 131 indicates that the ratio of Z11-/E11-14:Ac in the final 132 pheromone blend is determined by the fatty-acyl reduc- 133 tion step (Roelofs et al., 1987; Zhu et al., 1996), which 134 is the proposed site of PBAN action as shown in B. mori 135 (Ozawa \& Matsumoto, 1996). Then, a locus encoding a 136 stereo-selective PG fatty-acyl reductase (pgFAR) was 137 identified as the gene responsible for the dimorphism in 138 female pheromone production (Lassance et al., 2010). 139 The Z-strain ECB is more widespread in both Europe 140 and North America, whereas the E-strain occurs in cer- 141 tain areas within the geographical range of the Z-strain, 142 often in sympatry (Klun \& Cooperators, 1975; Anglade 143 et al., 1984; Peña et al., 1988; O'Rourke et al., 2010). In 144 Hungary, the Z-strain is likely to be the only one present 145 based on male trapping surveys and chemical analyses 146 of field-collected females (Anglade et al., 1984; Peña 147 et al., 1988; Kárpáti et al., 2016).

148

In ECB moths, previous research has detected PBAN- 149 like biological activity and immunoreactivity in three sets 150 of neurosecretory cells of the SG and in the corpora 151 cardiaca (Ma \& Roelofs, 1995a,b). These observations, 152 along with in vitro experiments employing synthetic 153 Bommo-PBAN and isolated PGs, have indicated that 154 PBAN-related neuropeptides in Os. nubilalis act directly 155 on the PG cells to stimulate sex pheromone production 156 (Ma \& Roelofs, 1995c). The involvement of PBAN- 157 related peptides in the sex pheromone biosynthesis of 158 ECB has been further supported by identification of the 159 receptors of the Ostnu-PBAN and Ostnu-DH neuropepti- 160 des (Nusawardani et al., 2013). Here, we describe the 161 exon-intron structure of the Ostnu-PBAN gene and the 162 amino acid sequence of the Ostnu-PBAN precursor 163 deduced from the cDNA sequence. Developmental- and 164 tissue-specific mRNA expression of the Ostnu-PBAN 165 gene was examined using quantitative real-time PCR. 166 Functional analyses on the hormonal activity of the 167 newly identified Ostnu-PBAN were also performed. 168

\section{Results}

Pheromone strain typing

Consistent with previous observations, we found only Z- 171 strain ECB moths in Hungary. Furthermore, Z-strain 172 ECBs were also collected from Sweden and Turkey and 173 those belonging to the $E$ type were sampled from 174 Slovenia. Details of collection procedures and phero- 175 mone identification are provided in the Experimental pro- 176 cedures section. 


\section{Cloning of Ostnu-PBAN cDNA}

In an attempt to isolate cDNA(s) encoding the DH-PBAN precursor in ECB, we used degenerate primers designed from two conserved regions of known lepidopteran DH-PBAN precursors. Single reverse transcription PCR (RT-PCR) products of the expected size of $288 \mathrm{bp}$ were generated from brain-SG complexes of both Eand Z-strain females separately and cloned into the pJET1.2 vector. Conceptual translation of these sequences revealed 84 and $64 \%$ amino acid identity with $\mathrm{DH}$ PBAN precursors of Omphisa fuscidentalis and B. mori, respectively. This homology indicates that the predicted peptide belongs to the family of DH-PBAN precursors.

The full-length DH-PBAN cDNA was obtained by $5^{\prime}$ and $3^{\prime}$-rapid amplification of cDNA ends (RACE) using eight total RNA samples extracted independently from ECBs collected at different geographical sites representing bivoltine $\mathrm{E}$, univoltine $\mathrm{Z}$ and bivoltine $\mathrm{Z}$ populations. Subsequent RT-PCR amplifications were conducted using primers designed based on the terminal segments of the $5^{\prime}$ - and $3^{\prime}$-RACE products. A total of 39 full-length transcripts were assembled, which were assigned to the ECB collections designated as SIE (Slovenia, E-strain, laboratory culture), KHuZ (Kéty, Hungary, Z-strain, laboratory culture,) BHuZ (Bicske, Hungary, Z-strain), RSwZ (Ravlunda, Sweden, Z-strain) and LSwZ (Landskrona, Sweden, Z-strain), and numbered sequentially. The transcripts fell into three classes based on their $3^{\prime}$ untranslated region (UTR) length: short $(\sim 1.9 \mathrm{~kb})$, intermediate ( $\sim 2.0 \mathrm{~kb})$ and long ( 2.1 kb), occurring in 27, 60 and $13 \%$ of sequences, respectively. To obtain a nonredundant sequence data set for each geographical region, repeated sequences above the arbitrary $98 \%$ nucleotide identity were removed from sequences of each of the five ECB collection sites, separately. The remaining sequences were then examined using a recombination detection program RDP4 and three putative recombinants (BHuZ2, BHuZ3 and BHuZ4) were identified, all occurring in ECB females caught at Bicske, Hungary. These presumed chimeric sequences were also removed, and thus a total of 14 sequences were included in the final data set.

The full-length transcripts contained a 60-bp $5^{\prime}$ UTR and a 603-bp open reading frame (ORF). The deduced amino acid sequence revealed a 200-residue precursor protein (Fig. 1). A total of 40 variable sites were found within the ORF, of which 27 were parsimony informative. These base substitutions comprise 32 transitions and eight transversions (Fig. 2). Three of the mutations result in amino acid substitutions of A13S, L18F and A180S, respectively. Two mutations (A13S and A180S) are at parsimony informative positions (Fig. 2) and provide potential phosphorylation sites for serine/threonine kinases. The deduced protein contains a hydrophobic N- 231 terminus, indicating a signal peptide with a potential 232 cleavage site between A21 and V22 (Fig. 1). The 24233 amino acid residues spanning V22 to L45 contain a con- 234 served C-terminal pentapeptide fragment FGPRL fol- 235 lowed by a G-K-R sequence, serving as a signal for C- 236 terminal amidation and proteolytic processing (Bradbury 237 \& Smyth, 1991; Veenstra, 2000). This 24-residue pep- 238 tide shares high sequence similarity with lepidopteran 239 $\mathrm{DH}$ peptides (Fig. 3). Four additional amidated peptides $240 \mathrm{~F} 3$ sharing characteristics of the PK/PBAN family of neuro- 241 peptides are also predicted to be proteolytically proc- 242 essed from the 200-amino acid ECB precursor, including: 243 a 37-aa Ostnu-PBAN (L128-L164) and three short 244 SGNPs, a 7-aa a-SGNP (V96-L102), a 20-aa b-SGNP 245 (S105-L124) and an 8-aa g-SGNP (T167-L174) (Fig. 1). 246 All of these putative peptides are flanked by K-K, G-R or 247 G-R-R sequences at their N-termini and G-R, G-K-R or 248 $\mathrm{G}-\mathrm{R}-\mathrm{R}$ sequences at their $\mathrm{C}$-termini, which are predicted 249 recognition sites for endoproteolytic cleavage and are 250 potentially amidated at their C-termini owing to the pres- 251 ence of Gly residues at the cleavage sites (Fig. 1). They 252 share a common C-terminal pentapeptide motif $F(T / 253$ S) $P(R / K) L$ and show homologies to other members of the 254 PK/PBAN peptide family (Fig. 3). In accordance with their 255 close taxonomic relationship, the Ostnu-PBAN precursor 256 showed high sequence conservation amongst the cram- 257 bid species. Excluding the signal peptide, it is 87 and 258 $76 \%$ identical to DH-PBAN precursors of the bamboo 259 borer (Om. fuscidentalis) (GenBank AFP87384), and the 260 legume pod borer (Maruca vitrata) (AFX71575), respec- 261 tively (Fig. 3). Lower homology (66-68\%) was observed 262 with the DH-PBAN precursors of B. mori and H. zea (Fig. 263 3). Last but not least, Ostnu-PBAN had 98.4\% nucleotide 264 identity and complete amino acid sequence identity to 265 a hypothetical gene (GenBank accession number 266 LC002981) in the Asian corn borer (Ostrinia furnacalis). 267

The $3^{\prime}$ UTR sequences of Ostnu-PBAN mRNA ranged 268 from 1250 to 1486 nucleotides, excluding the poly(A) 269 tail. Sequence analysis of the $3^{\prime}$ UTR indicated that 270 amongst the 1117 bases (excluding alignment gaps), 271 there were 170 variable sites (15.2\%) and 124 informa- 272 tive ones. A total of 67 indels with an average length of 273 11.8 bp were indicated, of which 40 were parsimony 274 informative. Two large (> 50 bp) indels were observed, 275 which discriminate the Ostnu-PBAN mRNA size variants 276 from each other (Fig. 4A). A BLAST search indicated 277 F4 that a 165 -bp portion of the $171 / 176 \mathrm{bp}$ insertion has 278 $94 \%$ identity to a reverse complement sequence of an 279 intron in the cadherin-like protein gene of Os. nubilalis 280 (GenBank DQ000165, bases 9405-9552 and 9689- 281 9702). The other large insert of $97 / 98$ bp contains one 282 copy of a $\sim 45$-bp direct repeat sequence of the $5^{\prime}$ flank- 283 ing region in which two 7-15 bp T-rich elements are 284 


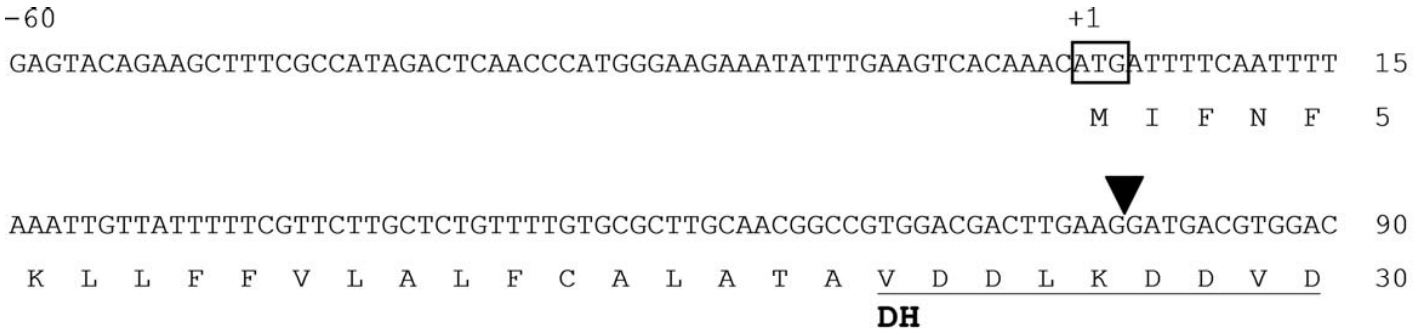

CGAGGCGCCAGCGACCGCGGCACCCTCTGGTTTGGCCCGCGACTCGGCAAGCGCTCCTTGAGGATATCAAATGAC 165

$\begin{array}{llllllllllllllllllllllllllll}\mathrm{R} & \mathrm{G} & \mathrm{A} & \mathrm{S} & \mathrm{D} & \mathrm{R} & \mathrm{G} & \mathrm{T} & \mathrm{L} & \mathrm{W} & \mathrm{F} & \mathrm{G} & \mathrm{P} & \mathrm{R} & \mathrm{L} & \boldsymbol{G} & \boldsymbol{K} & \boldsymbol{R} & \mathrm{S} & \mathrm{L} & \mathrm{R} & \mathrm{I} & \mathrm{S} & \mathrm{N} & \mathrm{D} & 55\end{array}$

GACAACAAGCAAACCTTCCTGAGGCTTCTTGAAGCTGCCGACGCCTTAAAATTCTACTACGATCAGCTCCCCTTC 240

$\begin{array}{llllllllllllllllllllllllll}\text { D } & \text { N } & \text { K } & \text { Q } & \text { T } & \text { F } & \text { L } & \text { R } & \text { L } & \text { L } & \text { E } & \text { A } & \text { A } & \text { D } & \text { A } & \text { L } & \text { K } & \text { F } & \text { Y } & \text { Y } & \text { D } & \text { Q } & \text { L } & \text { P } & \text { F } & 80\end{array}$

TACGAAAGCCAGGCCGACGATCCGGAGACCCGTGTGACAAAAAAGGTAGTCTTCACCCCGAAACTCGGTCGCAGC 315

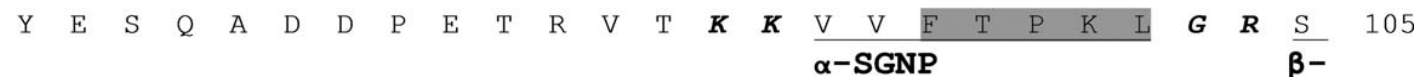

ATCGACGTCTACCCTGAAAAACGCACGTTCGAGAACGTAGAATTCACGCCGCGGCTGGGAAGAAGGTTGCCTGAG 390

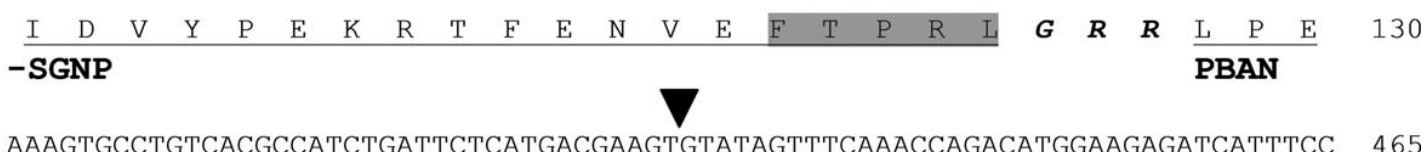$$
\begin{array}{llllllllllllllllllllllllll}
\text { K } & \text { V } & \text { P } & \text { V } & \text { T } & \text { P } & \text { S } & \text { D } & \text { S } & \text { H } & \text { D } & \text { E } & \text { V } & \text { Y } & \text { S } & \text { F } & \text { K } & \text { P } & \text { D } & \text { M } & \text { E } & \text { E } & \text { I } & \text { I } & \text { S } & 155
\end{array}
$$

CGGCACAACTACTTCTCACCGCGACTCGGCAGAACCCTCAACTTCTCTCCTAGACTGGGGAGGGAACTAGACTCT 540

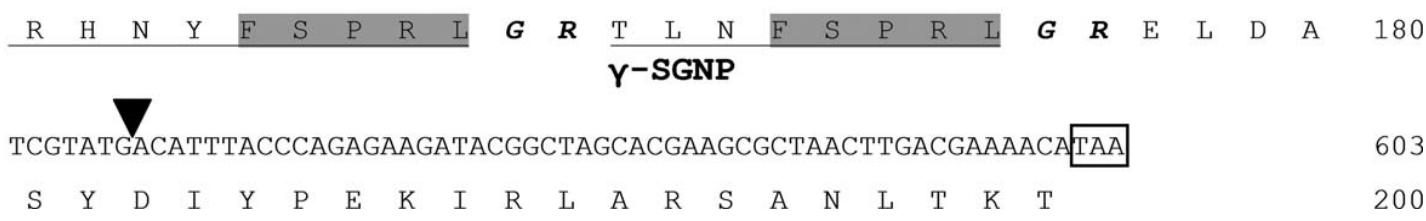

Figure 1. Nucleotide and deduced amino acid sequences of a putative Ostrinia nubilalis pheromone biosynthesis activating neuropeptide (PBAN) CDNA, designated as KHuZ1 (Kéty, Hungary, GenBank accession number: KU952100). The nucleotide 11 is the A of the ATG-translation initiation codon. Potential endoproteolytic cleavage sites are highlighted in bold italics. Amino acids of the five putative FXPRL- $\mathrm{NH}_{2}$ peptides are underlined: diapause hormone (DH), a-, b-, g-suboesophageal ganglion neuropeptides (SGNPs) and PBAN. Residues of the conserved C-terminal pentapeptide sequence are highlighted against a grey background. The initiation and termination codons are boxed. Positions of introns are indicated by black inverted triangles.

found (Fig. 4B). Two short (10- and 12-bp) palindromic sequences, a 10-bp direct repeat and a 16-bp inverted repeat were also found within the $3^{\prime}$ UTR (Fig. 4B). A search for putative regulatory sequences revealed $\mathrm{AU}$ rich elements, eg ATTTA, which is present four times in the $3^{\prime}$ UTR. Although there is a potential polyadenylation signal sequence (AATAAA) at 288-291 bp downstream from the translational stop codon, and a second polyadenylation signal further downstream within the 171/ 176 bp insertion (Fig. 4B), we could not detect any mRNA species that might have resulted from the use of these upstream polyadenylation signals.
mRNA expression during development

Expression of DH-PBAN mRNA was determined in 298 immature and adult stages of ECBs by real-time PCR 299 with primers designed against conserved regions. We 300 observed very similar expression patterns between the 301 tissues and stages of the E- and Z-strain ECB, hence, 302 only data from E-strain borers are shown (Fig. 5). 303F5 Amongst the immature stages, Ostnu-PBAN mRNA was 304 not detected in freshly laid eggs (data not shown). In 305 whole larvae, transcript levels were relatively high in first 306 and second instars, but declined as larvae grew older. 307 Low expression was detected in whole pupae, about two 308 


\section{Nucleotides}

0000011111112222222233333333333444444455

3356612488880145588902344667799011457903

7923676703494302558794925395836517494848

KHuz1 GTCCGCCGCCCGTGCGCGACCCTTCGACGAGGGTACCGCG

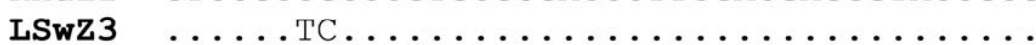

SlE7 T...GTCTTT........ACG......T.G.TAT.

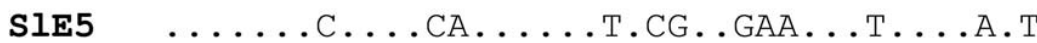

RSwZ2 T..TA...........T.CG..GAA..T....

KHuz2 .......TT.CAT.T...ACG..GAA..T.....

SIE4 T.T...........TT.C..TG.AGAA.C....

RSwz1 T.............TT.C..TG.AGAA.C....

LSwZ4 .C..... .TT.C............A.C....

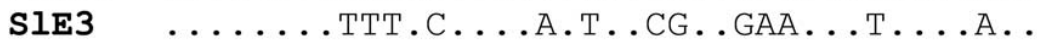

LSwZ5 .......TTACA...GT...T.GAA........

S1E6 T......ТT.САТ.T...ACG...........

BHuz1 .......ТT.CAT.T...ACG........ .А.

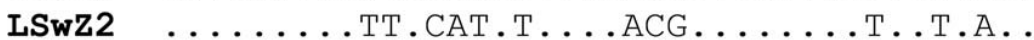
1313333333133333333333333333333333333311
Amino

acids

001

118

380

ALA

...

S..

..S

S.S

...

SE.

...

S.

‥

...

S..

...

$\ldots$

$++$

Figure 2. Distribution of polymorphic nucleotide and amino acid sites in the coding region of 14 Ostrinia nubilalis pheromone biosynthesis activating neuropeptide cDNAs from E-strain (SI, Žalec, Slovenia) and Z-strain (BHuZ, Bicske, Hungary; KHuZ, Kéty, Hungary; RSwZ, Ravlunda, Sweden; LSwZ, Landskrona, Sweden) Ostrinia nubilalis. The sequences are numbered consecutively for each geographical area. The KHuZ1 sequence (KU952100) is used as a reference. Site positions are numbered vertically from the start codon of the reference sequence. The position for each polymorphic site within a codon is shown below. Informative sites are marked by 1 signs. Dots indicate nucleotide identity.

$\mathrm{DH}$

O. nubilalis
O. fuscidentalis
M. vitrata
B. mori
H. zea

O. nubilalis O. fuscidentalis

M. vitrata

B. mori

H. zea

O. nubilalis O. fuscidentalis

M. vitrata

B. mori

H. zea

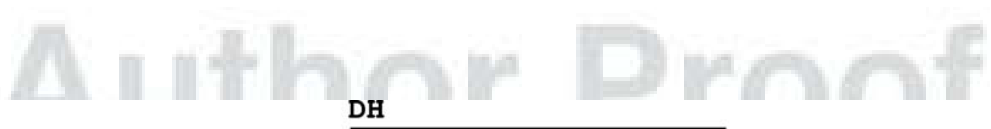

M-IFNFKLLFFVLALFCALATAVDDLKDDVDRGA-SDRGTLWFGPRLGKRSLRISNDDNKQTFLRLLEAADALKF 73 MSIFNLKFVLS IFALFCGFATAVDDLKDEADRGA-SDRGTLWFGPRLGKRSLRISNDDNRQTFLRLLEAADALKF 74 MSSLNFKVLFYIFFL-CGVSVALDDSKDEVDRGA-SDRGGLWFGPRLGKRSLRVNNDDNRQTFLRLLEAADALKY 73 MYKTNIVFNVLALALFSIFFASCTDMKDESDRGAHSERGALWFGPRLGKRSMKPSTEDNRQTFLRLLEAADALKF 75 MFNQTQLFVFLAVFTTSSVLGNNNDVKDGAASGAHSDRLGLWFGPRLGKRSLRISTEDNRQAFFKLLEAADALKY 75

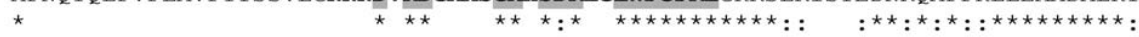

$\alpha$-SGNP $\beta$-SGNP $\quad$ PBAN

YYDQLPFYESQADDPETRVTKKVVFTPKL GRSIDVYPEKRTFENVEFTPRLGRRLPEKVPVTPSDSHDEVYSFKP 148 YYDQLPFYESRADDPETRVTKKVIFTPKLGRSMDGYSDKRTYENVEFTPRLGRRLPEKLSVTPSDSHDAVYSFKP 149 YYDQLPFYDSQVDDPETRVTKKVVFTPKLGRSIGGVFQDKKYDNVEFTPRLGRRIPDALPVTPSD--DDVYSFKP 146 YYDQLP-YERQADEPETKVTKKIIFTPKLGRSVA---KPQTHESLEFIPRLGRRLSEDMPATPAD--QEMY--QP 142 YYDQLP-YEMQADEPETRVTKKVIFTPKLGRSLA--YDDKSFENVEFTPRLGRRLSDDMPATPAD--QEMY--RQ 143

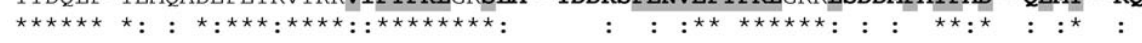

$$
\gamma-\text { SGNP }
$$

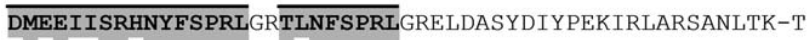
EMSELDSRNNYFSPRLGRTVNFSPRLGREL--SYDIYPEKIRLARSINLTK-T DSGEVDRRTSYFNPRLGRKVSFSPRLGREL--TYDIYPEKIRLARSANDSKAT DPEEMESRTRYFSPRLGRTMSFSPRLGREL--SYD-YPTKYRVARSVNKTMDN DPEQIDSRTKYFSPRLGRTMNFSPRLGREL--SYDMMPNKIRVVRSTNKTRST

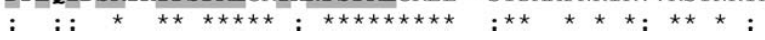

\section{5}


A

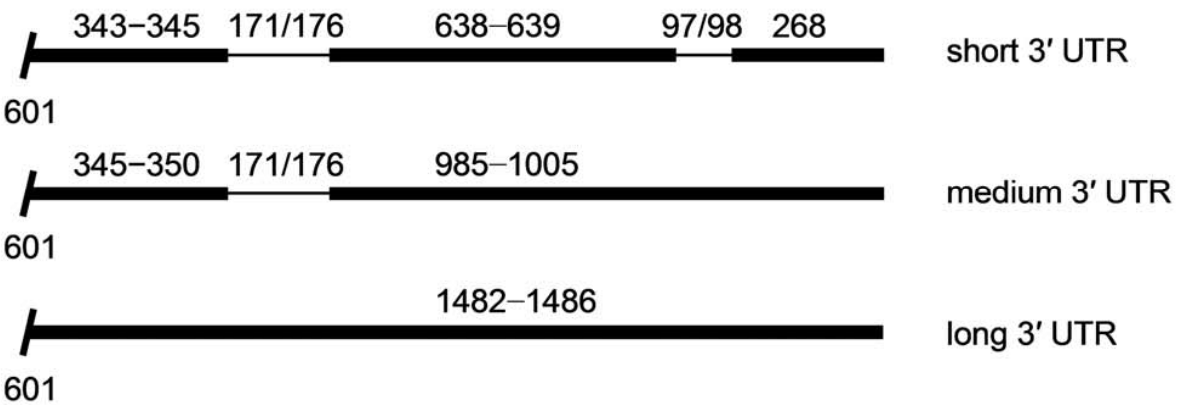

B

TAAGGCGATGACCTTATATAAATCTTTACCGTTTTAACTGATGTTTGACGATACCTCTGTAATTTTAATACGATA 675 TTGTTTACGAAAGGGTAGTTTTTAAATAACGATGCCATTTTGTATTTGAAGAATGGACCAAAGACTTTTAAGCAC 750 GGATTTTGAAATGACACTCATGCTCAAGAAAAAGTTGAAGCACGCTTTTGGTTCAAAAATACTATAATATTAACC 825 AATCATAgGATACATGATTGAGTTTCAATCAGCGAGGTTTATAGCTACTTACATTAGTAATTGGTA AATAAATGC 900 AGTTTAAAAAGCACTCCATCTAGGCAAGTTACCAAGGATATGAACGCTAAGACCATAGATCACAGAAACAGTAAT 975 AAAGATTATTCGAACGTTGAGTATTGATACCGCAGTGGATAATGAGCACATAGGTACCTATTTTTATACTTTGTG 1050 TGTGTGAATTTCTAATGCGACACTGAGTTTCGAACTCAGCGCATTAGTTGGCATCTCTCTATATCTCTATGGCTA 1125 CGACCGAAAGAGCGCTGAAAAGTCTAAAGTCTCCGCAAGGCAAGGAGAGAGAATGGTGCAGAGTTTAGCCCAACC 1200 TTGGACAAGGAATGGGATAAAGTGAAATCAAGCTGATGAAGTGGTTTGACTGCCAAAGGCACGTGATCGTCACAA 1275 ACTGTATAGATTCTGCAGTTTGCCTAAAACTAGTTTCTAGTTCATTCTATTATATTTGTGTATGAAAATAGGAGT 1350 CTTTATAGGCTGGGGACTCCTAAGCTGAACACTTAGAGCTTGTAGATTTGTGTTTAAATTTACTAGTTACGCTCA 1425 AATCTCGATTTAATTTGATTGTTTGTAAAGGCAAAAAGTTAAAAACCAAAGGCTGTAATTTGTTCTTGAGCAAAG 1500 ATTCTATGTTAGTGTCATTTCATAATACCCCTACCTCTTTTTCTTCTTCAAGCAATCTATTAAAATTGATCTCTT 1575 GGATTCGTTCGACTTCTTATTGACTCGTCTCACTCTCTAAGAGCTTCTTGAAATGACCGTTTTCAAACTAGATAC 1650 TTAATAGCAGATCCGTCCATCGAgTCAGTTTTCTTTCATGCCCTATCTTTTTTCAATGAGGTTGCAATACCA TTGTTTTTTAATGTCTCAGACTTAGGATCCTTAATAATTGGATTTTTTTTTATTATATCATGCCCTATTTTGTTT 1800 TATGAGATTGCAATACCAAAAGCACCCTAGACTTTGTTCTTCGTAGACTAAAAAGAACTAAAAAACTAAACTTAT 1875 AACGGCGTCTTTCTAAAGTTAAGCGGTCAAAAAAGTTGCATAATTTTACAATTATGACGTAAAATTATAAAAAAA 1950 ATGGCCGCTTCATACCTCATTCTTAGATTGTAACACGTTAATGTTTTGGACGATATTATTGTTATAAAATACGTA 2025 TACATTAAACTAGATTGTAAgCGATATTTATGAGAATTTAATAAAAATAATTGCTG (poly (A) 2082

Figure 4. (A) Schematic representation of the distribution of long (>50 bp) insertions/deletions in the $3^{\prime}$ untranslated regions (UTRs) based on a CLUSTALX alignment of Ostrinia nubilalis pheromone biosynthesis activating neuropeptide (Ostnu-PBAN) cDNA sequences. The lengths of the deletions and flanking sequences [without the poly(A) tail] are indicated above the lines. Nucleotide position 601 (numbered relative to the A of the ATG initiation codon) is the first base downstream from the stop codon. (B) The $3^{\prime}$ UTR of KHuZ1 (Kéty, Hungary, KU952100), a long variant of the putative Ostnu-PBAN cDNA (nucleotides 661 to 2142). Long (> $50 \mathrm{bp}$ ) insertions are shown in bold; the inverted intronic sequence present within an insert is dashed-underlined. Direct repeats are shaded in grey and marked with arrows above the sequences. Inverted repeats are indicated by arrows only. Palindromes are marked by converging arrows. Dots within the arrows indicate mismatches. Dotted lines above the sequences represent T-rich stretches adjacent to the repeated sequences. The termination codon (TAA) and the polyadenylation signals (AATAAA) are boxed. 


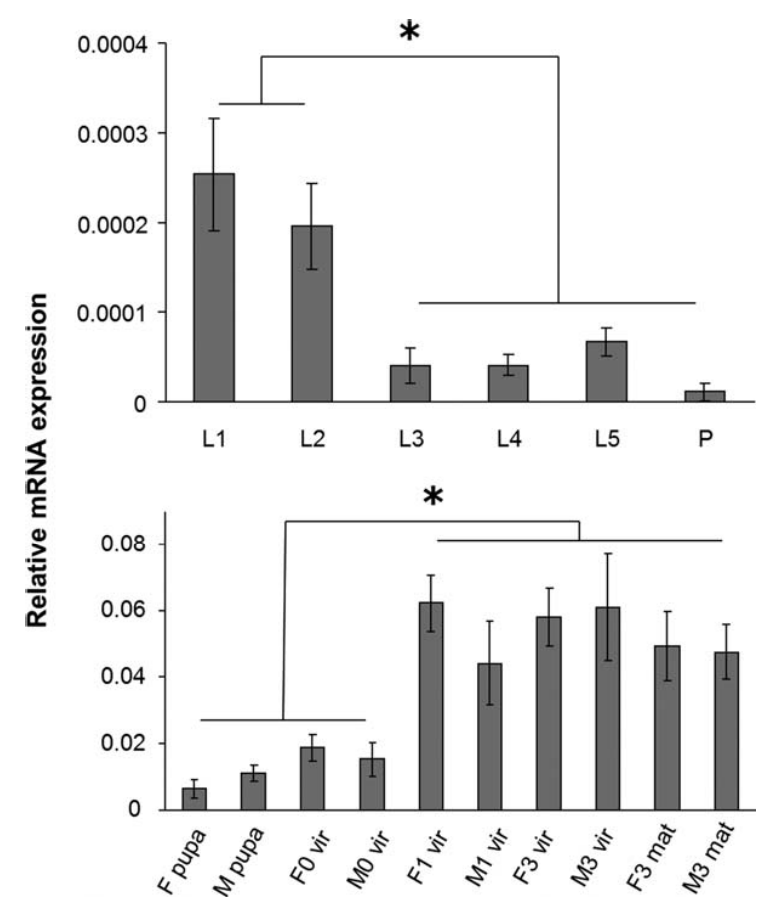

Figure 5. Relative diapause hormone pheromone biosynthesis activating neuropeptide gene expression in whole larvae and pre-emergence pupae (top) and in brain-suboesophageal ganglion complexes of adults (bottom) of Ostrinia nubilalis. The mRNA expression was normalized to expression of ribosomal protein S3. L1-L5, first to fifth instars; P, pupae; vir, virgin; mat, mated; F0, F1, F3, females on day 0, 1 and 3 after emergence, respectively; M0, M1, M3, males on day 0, 1 and 3 after emergence, respectively. Mean values 6 SEM of three biological replicates are shown. Statistical analysis was performed by analysis of variance followed by Duncan's multiple range test. Asterisks indicate significant differences at $P<0.05$. orders of magnitude lower than in isolated pupal brain-SG preparations (Fig. 5). Analysis of the expression pattern in brain-SG complexes revealed high amounts of Ostnu-PBAN transcript in 1-3-day-old females and males regardless of their mating status, and lower amounts in newly emerged females and preemergence pupae (Fig. 5). No appreciable expression of Ostnu-PBAN was detected in other tissues and organs of adults, including leg muscles, ovaries, fat bodies, PGs and hairpencil-aedeagus complexes (data not shown).

\section{Biological activity of Ostnu-PBAN}

The predicted C-terminal amidated 37-residue OstnuPBAN was synthesized and injected into female ECB moths to test for pheromonotropic activity. Its doseresponse relationship was examined in E-strain ECB females using a decapitated-moth bioassay. The synthetic Ostnu-PBAN significantly stimulated the production of E11-14:Ac in a dose-dependent manner (Fig. 6). Gas chromatographic and mass spectrometric (GC-MS) analysis revealed that a dose of 0.058 pmol per insect

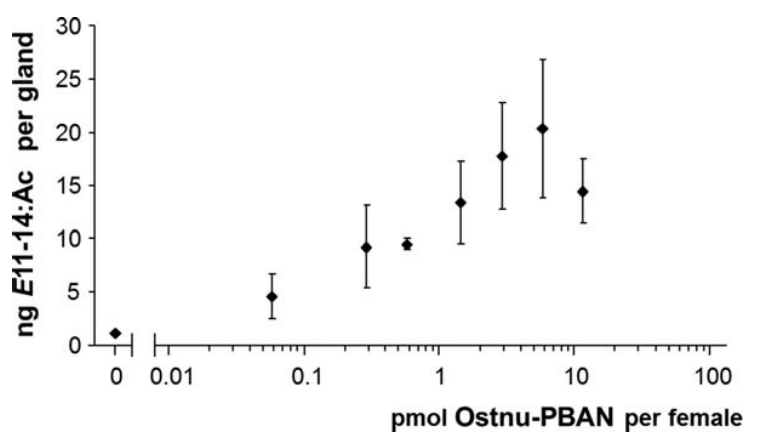

Figure 6. The dose-response effect of synthetic Ostrinia nubilalis pheromone biosynthesis activating neuropeptide (Ostnu-PBAN) on the amounts of $(E)$-11-tetradecenyl acetate (E11-14:Ac) in pheromone gland extracts from decapitated E-strain Os. nubilalis females. Two-day-old females were decapitated at the third hour of scotophase and $27 \mathrm{~h}$ later were injected with a dose series of synthetic Ostnu-PBAN $(0.058,0.29,0.58,1.45,2.9$, 5.8 and $11.6 \mathrm{pmol}$ in $2 \mathrm{~m}$ distilled water). Females injected with $2 \mathrm{~m}$ water served as controls. Error bars show the SEM of six biological replicates, each containing three pheromone glands.

was sufficient for significant $(P<0.05)$ activation of 329 pheromone biosynthesis when injected into 3-day-old 330 decapitated females, and resulted in the production of 331 4.66 2.1 ng E11-14:Ac per female, as compared to the 332 control level of 1.0860 .06 ng E11-14:Ac (Fig. 6). Maxi- 333 mum pheromone production (17.26 4.56 E11-14:Ac ng/ 334 PG) was achieved at a dose of 5.8 pmol Ostnu-PBAN. 335 However, increasing the dose to 11.6 pmol per female 336 resulted in a slight (about 28\%) decrease in pheromone 337 production (Fig. 6).

The GC-MS analysis of pheromone gland extracts 339 revealed an average content of $14.565 .88 \mathrm{ng} / \mathrm{PG}$ E11- 340 14:Ac in 0- to 3-day-old virgin females and 3.26 1.16341 ng/PG Z11-14:Ac in Z-strain ones (Fig. 7). Decapitation 342 F7 resulted in a decline in pheromone titres in both $\mathrm{E}$ - and 343 Z-strain moths. As expected, mated females also pro- 344 duced significantly less pheromone than virgins. How- 345 ever, in both cases, injection of 5.8 pmol Ostnu-PBAN 346 stimulated pheromone production close to a normal level 347 (Fig. 7).

\section{Gene organization}

349

Genomic DNA sequences were obtained from ECBs 350 collected at four locations in Hungary (Bicske, 351 Hódmezővásárhely, Martonvásár and Romhány), one 352 from Adana (Turkey) and one from the Savinja valley 353 (Slovenia). In addition, a male and a female adzuki bean 354 borer moth (Ostrinia scapulalis Walker; caught at Mat- 355 sudo, Japan) were also included in the present study. 356 The intron-exon structure of the DH-PBAN gene was 357 determined by alignment of the cDNA and corresponding 358 genomic sequences. Sequencing across the intron-exon 359 junctions of the genomic fragments revealed five introns 360 (Fig. 1). Intron sizes and intron-exon boundaries are 361 

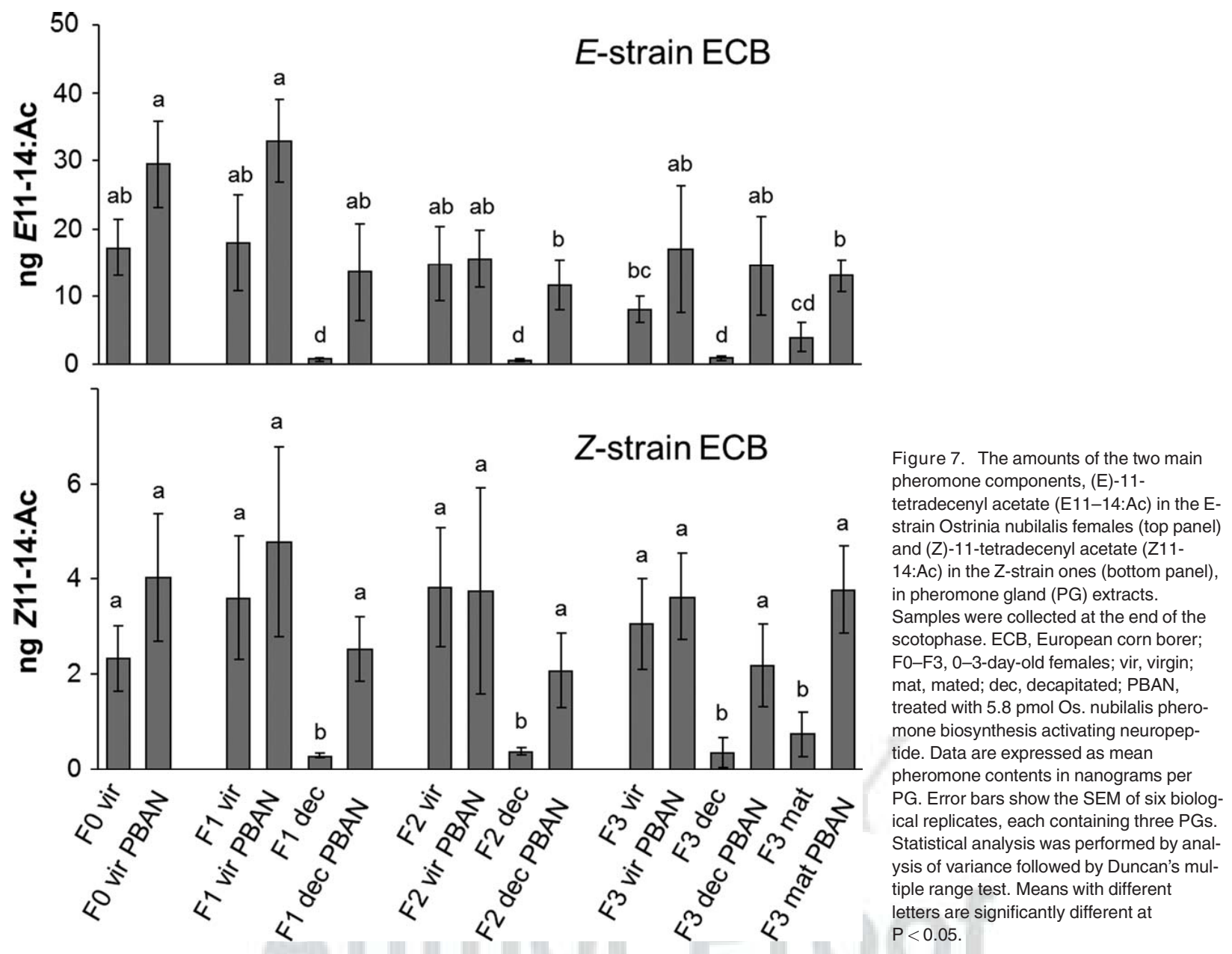

summarized in Tables 1 and 2, respectively. The putative peptides derived from these exons are: exon one-signal peptide and the $\mathrm{N}$-terminal portion of $\mathrm{DH}$, exon two-Cterminal portion of $\mathrm{DH}$, exon four-a- and b-SGNPs along with the N-terminal portion of PBAN, exon five-the remaining portion of PBAN and the gSGNP (Fig. 1). The C-terminal codons and the complete $3^{\prime}$ UTR are encoded in exon six. All five intron-exon junctions in the OstnuPBAN gene have appropriate consensus signals for splicing: a $5^{\prime}$ dinucleotide GT and a $3^{\prime}$ AG (Table 2). Intron phases within the Ostnu-PBAN gene were $0,2,1,2,1$, respectively. Analysis of the DH-PBAN genomic sequences revealed that the deduced amino acid sequences of Os. scapulalis DNA fragments were identical to the consensus sequence of the Ostnu-PBAN precursor (Table 2).

\section{Neighbour-joining analysis}

To examine the sequence relationships amongst Ostnu-PBAN mRNAs, a neighbour-joining tree was generated. Regardless of the pheromone composition and geographical origin of each ECB sample, all transcripts containing a short $3^{\prime}$ UTR formed a separate clade with 382 $100 \%$ bootstrap support (Fig. 8). This result can be 383 F8 understood in the light of our observation that all 384 sequences with a short $3^{\prime}$ UTR (SIE6, BHuZ1, LSwZ2) 385 were $>99 \%$ identical to each other. Another three 386 sequences (SIE7, KHuZ1, LSwZ3), sharing 92-97\% 387 identity, fell into the long $3^{\prime}$ UTR group and formed a 388 separate clade with $85 \%$ support. However, transcripts 389 with a medium-length $3^{\prime}$ UTR (SIE3-5, LSwZ5, RSwZ1- 390 2, KHuZ2) that shared 91 to $96 \%$ identity were assigned 391 to four distinct clades (Fig. 8).

392

Discussion

By means of a molecular cloning approach, we identified 394 PK/PBAN neuropeptides from brain-SG complexes of 395 Os. nubilalis. Our data, presented here, indicate that the 396 ORF of Ostnu-PBAN encodes a putative neuropeptide 397 precursor of 200 amino acid residues. The deduced 398 amino acid sequence revealed a 24-aa DH, a 37-aa 399 PBAN and three additional short peptides (a-, b- and g- 400 SGNPS) derived from post-translational proteolytic 401 
Table 1. DNA fragments obtained from Ostrinia nubilalis and Ostrinia scapulalis diapause hormone pheromone biosynthesis activating neuropeptide (DHPBAN

\begin{tabular}{|c|c|c|c|c|}
\hline Origins ( $E / Z$ strain) & Male, female, larva & Exons (nucleotide positions) & Introns (intron lengths in bp) & Most similar cDNAs (\% identity) \\
\hline \multicolumn{5}{|l|}{ Os. nubilalis genomic DNA fragments. } \\
\hline \multirow[t]{4}{*}{ Adana, Turkey (Z) } & M1 & IV-V (375-529) & IV (640) & SIE6, BHuZ1, LSwZ2 (100) \\
\hline & M2 & IV-VI (313-583) & IV (640), V (528) & SIE6, BHuZ1, LSwZ2 (100) \\
\hline & M3 & IV-V (375-529) & IV (474) & SIE7 (100) \\
\hline & & VI (559-1841) & - & LSwZ5 (99.5) \\
\hline \multirow[t]{4}{*}{ Bicske, Hungary $(Z)$} & M4 & $\mathrm{I}-\mathrm{V}(-49-529)$ & I (745), II (893), III (417), IV (534) & BHuZ1, LSwZ2 (99.2) \\
\hline & & VI (559-1774) & - & LSwZ2 (99.7), SIE6 (99.5) \\
\hline & & $|-| \mid(-49-128)$ & I (935) & SIE2, SIE5, LSwZ3 (100) \\
\hline & M5 & IV-V (375-529) & IV (671) & LSwZ4 (99.4) \\
\hline Martonvásár, Hungary (Z) & M6 & IV-V (375-529) & IV $(640)$ & SIE6, BHuZ1, LSwZ2 (100) \\
\hline \multirow[t]{5}{*}{ Hódmező- vásárhely, Hungary (Z) } & L1 & IV-V (375-529) & IV (587) & KHuZ2 (100) \\
\hline & & IV-V (375-529) & IV (474) & SIE7 (100) \\
\hline & & VI (559-1819) & - & KHuZ2 $(99.5)^{\star}$ \\
\hline & L2 & IV-V (375-529) & IV (474) & SIE7 (100) \\
\hline & & VI (559-1820) & - & SIE4 (100), RSwZ1 (99.9) \\
\hline \multirow[t]{7}{*}{ Romhány, Hungary (Z) } & L3 & IV-V (375-529) & IV (474) & SIE7 (100) \\
\hline & & VI (559-1743) & - & SIE6, LSwZ1 (99.8) \\
\hline & L4 & IV-V (375-529) & IV (474) & SIE7 (100) \\
\hline & & IV-V (375-529) & IV (640) & SIE6, BHuZ1, LSwZ2 (100) \\
\hline & & VI (559-1818) & - & RSwZ2 $(99.5)^{\dagger}$ \\
\hline & L5 & VI (559-2012) & - & LSwZ3 (99.2) \\
\hline & L6 & VI (559-1974) & - & LSwZ3 (99.7) \\
\hline \multirow[t]{5}{*}{ Žalec, Slovenia (E) } & M7 & IV-VI (346-583) & IV (664), V (534) & SIE3 (99.3) \\
\hline & & IV-VI (346-583) & IV (436), V (511) & ND (94.6-96.7) \\
\hline & & VI (559-1847) & - & LSwZ2 (98.7)/LSwZ5 (99.6) \\
\hline & M8 & VI (619-2066) & - & KHuZ1 (99.7) \\
\hline & & VI (559-1821) & - & SIE3 (99.3) \\
\hline \multicolumn{5}{|l|}{ Os. scapulalis } \\
\hline \multirow{5}{*}{ Matsudo, Japan } & M9 & I-II (-41-128) & $\mathrm{I}(\sim 3 \mathrm{~kb})$ & BHuZ1, LSwZ2 (100) \\
\hline & & IV-VI (285-583) & IV (639), V (528) & SIE6, BHuZ1, LSwZ2 (100) \\
\hline & & VI (559-1743) & & SIE6 (99.7) \\
\hline & $\mathrm{F} 1$ & IV-V (313-529) & IV (650) & SIE3 (100) \\
\hline & & VI (559-1844) & - & ND (90.8-95.0) \\
\hline
\end{tabular}

Intron lengths are indicated (in bp).

Positions of the DNA fragments are given with respect to the translation initiation codon (nucleotides within introns are not numbered).

Each sequence was aligned with the cDNA-derived sequences, and the closest matches are presented in the last column.

The corresponding Ostnu-PBAN transcripts are designated as SIE3-SIE7 (Slovenia, E-strain), BHuZ1 and KHuZ1-KHuZ2 (Hungary, Z-strain), RSwZ1-

AQ45 RSwZ2 and LSwZ1-LSwZ5 (Sweden, Z-strain).

*, 'Excluding a 29 and a 26 bp indel, respectively.

${ }^{\ddagger}$ Mixed sequence, a 92 bp internal fragment is homologous to LSwZ2, the flanking sequences are homologous to LSwZ5

AQ46 ND, not determined: cDNA with $>98 \%$ identity was not found, the range of nucleotide identities amongst all 14 Ostnu-PBAN cDNAs are shown.

F, female; M, male; L, larva.

Table 2. Putative exon-intron structure of the Ostrinia nubilalis pheromone biosynthesis activating neuropeptide gene

\begin{tabular}{|c|c|c|c|c|c|c|}
\hline Exon number & Size (bp) & cDNA position & Splice acceptor & Splice donor & Intron phase & Amino acid \\
\hline 1 & $5^{\prime}$ UTR 178 & $-60-78$ & Not determined & TTGAAG gtaatt & 0 & Lys $^{26} / \mathrm{Asp}^{27}$ \\
\hline 2 & 95 & $79-173$ & tggcag GATGAC & CAACAA gtacgc & 2 & Lys $^{58}$ \\
\hline 3 & 101 & $174-274$ & ttgcag GCAAAC & CCCGTG gtaagt & 1 & $\mathrm{Val}^{92}$ \\
\hline 4 & 154 & $275-428$ & caacag TGACAA & CGAAGT gtgagt & 2 & $\mathrm{Val}^{143}$ \\
\hline 5 & 119 & $429-547$ & tttcag GTATAG & CGTATG gtatgt & 1 & $\mathrm{Asp}^{183}$ \\
\hline 6 & $5313^{\prime}$ UTR & $548-3^{\prime}$ end & ttccag ACATTT & Not determined & & \\
\hline
\end{tabular}

UTR, untranslated region.

Exon and intron sequences are shown in upper- and lowercase letters, respectively.

The nucleotide 11 is the A of the ATG-translation initiation codon.

Invariant nucleotides at the splice sites are underlined.

Amino acid(s) encoded at the splice site are indicated.

Phase 0 introns lie between two codons; phase 1 and 2 introns are located after the first and second positions of codons, respectively.

The $3^{\prime}$ ends are located 1850-2086 nucleotides downstream of the start codon.

$\forall 2017$ The Royal Entomological Society, 00, 00-00 


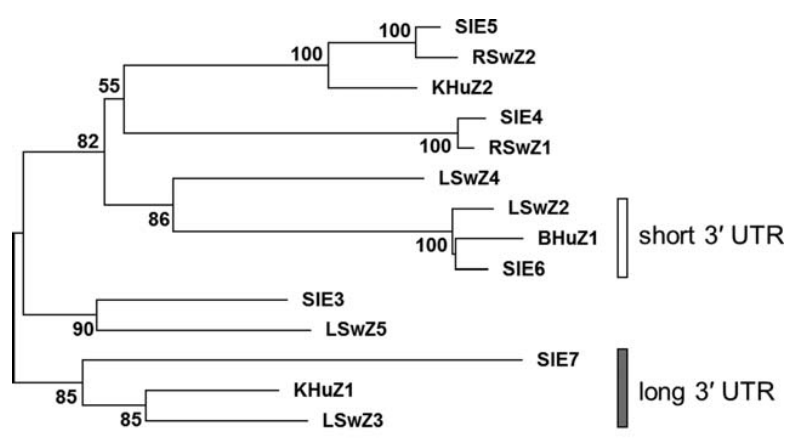

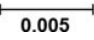

Figure 8. Neighbour-joining tree of 14 full-length cDNA sequences encoding the putative diapause hormone pheromone biosynthesis activating neuropeptide precursor from E-strain (SI, Žalec, Slovenia) and Z-strain (BHuZ, Bicske, Hungary; KHuZ, Kéty, Hungary; RSwZ, Ravlunda, Sweden; LSwZ, Landskrona, Sweden) Ostrinia nubilalis. The sequences are numbered consecutively for each geographical area. Sequences not belonging to one of the indicated clades have medium-length $3^{\prime}$ untranslated regions (UTRs). All positions containing gaps and missing data were eliminated from the data set. Bootstrap values $>50 \%$ (1000 replications) are indicated at the nodes. The scale bar represents the number of base substitutions per site.

processing and subsequent carboxyl-terminal amidation.

The consensus $F(T / S) P(R / K) L$ pentapeptide motif, representing the active core sequence for diverse biological activities (Nachman et al., 1986; Raina \& Kempe, 1990; Kuniyoshi et al., 1992), was found immediately upstream of the predicted endoproteolytic cleavage sites that contain a Gly residue for amidation of the C-terminus, which is critical for biological activity (Raina \& Kempe, 1990). The Ostnu-PBAN precursor has closest homology (84\% amino acid identity) with the DH-PBAN precursor of the bamboo borer, Om. fuscidentalis (Suang et al., 2015). Regier et al. (2012) conducted a molecular phylogenetic analysis of moth species in the Pyraloidea superfamily using sequence data from protein-coding regions of five nuclear genes. This molecular phylogeny suggested a sister relationship between the crambid subfamilies Pyraustinae (represented in the analysis by the Asian corn borer, Os. furnacalis and the fulvous-edged pyrausta moth, Pyrausta nexalis) and Spilomelinae, to which the legume pod borer, M. vitrata, and the bamboo borer, Om. fuscidentalis, belong. The close relatedness between Pyraustinae and Spilomelinae is further supported by our finding that the deduced amino acid sequence of Ostnu-PBAN consists of 37 residues, and, to our knowledge, a 37-residue PBAN has previously only been reported in Om. fuscidentalis (Suang et al., 2015).

The full-length Ostnu-PBAN cDNAs varied in size between 1910 and 2146 nucleotides due to the length variation in the $3^{\prime}$ UTR, which is otherwise exceptionally long (> $1250 \mathrm{bp}$ ) compared to the $3^{\prime}$ UTRs of known lepidopteran DH-PBAN genes (<200 bp). Various struc- 433 tural motifs that commonly affect mRNA stability and 434 translational efficiency are present in the $3^{\prime}$ UTR, sug- 435 gesting the possibility that Ostnu-PBAN may be regu- 436 lated by a miRNA-mediated post-transcriptional pathway 437 (Lucas et al., 2015).

A neighbour-joining analysis of nucleotide sequences 439 revealed that Ostnu-PBAN transcripts with relatively 440 short and long $3^{\prime}$ UTR sequences fell into separate 441 clades, whereas medium-sized transcripts comprise a 442 heterogeneous set of sequences. However, the sequen- 443 ces did not show any clustering according to pheromone 444 composition, geographical origin or life history (univoltine 445 vs. bivoltine). In another study, ECB moths were not dif- 446 ferentiated on the basis of D11 desaturase allelic diver- 447 sity (Geiler \& Harrison, 2010). The variation in intron 448 length in the two D11 desaturase allelic classes did not 449 separate ECB moths according to their pheromone race, 450 geographical origin or voltine ecotypes. Currently, only a 451 limited number of loci are known to differ between $E$ and 452 $Z$ strain ECB moths. These are pgFAR (Lassance et al., 453 2010), and some $Z$ chromosome-linked markers, the Tpi 454 (Dopman et al., 2005) and three pheromone receptor 455 genes (Lassance et al., 2011; Yasukochi et al., 2011). 456

Sequencing of the entire coding sequence and exon- 457 intron boundaries of the Ostnu-PBAN gene revealed that 458 it is at least $5 \mathrm{~kb}$ long and consists of six exons and five 459 introns with a conserved distribution of intron positions 460 within codons $(0,2,1,2,1)$. The Ostnu-PBAN gene has 461 extensive structural homology to the B. mori (Xu et al., 462 1995a), Helicoverpa armigera (Zhang et al., 2005), Clos- 463 tera anastomosis (Jing et al., 2007) and M. vitrata 464 (Chang \& Ramasamy 2014) DH-PBAN genes, which 465 have previously been identified in the genomes of lepi- 466 dopteran species belonging to various families. Short- 467 and medium-length $3^{\prime}$ UTR forms were also observed in 468 the amplification products obtained from adzuki bean 469 borer (Os. scapulalis) DH-PBAN genomic DNA, whose 470 deduced amino acid sequence shared $100 \%$ identity 471 with the Ostnu-PBAN consensus sequence. An Asian 472 corn borer, Os. furnacalis, genomic DNA sequence 473 (LC002981) contains the entire exon 3 and exon 4 and 474 flanking intronic sequences of a gene putatively encod- 475 ing a DH-PBAN precursor. This fragment encodes for a- 476 SGNP, b-SGNP and the N-terminal portion of Ostfu- 477 PBAN, and exhibits $98.4 \%$ nucleotide identity and the 478 deduced amino acid sequence of the encoded protein is 479 $100 \%$ identical to Ostnu-PBAN SIE5 and RSwZ2. All this 480 evidence implies that the observed nucleotide polymor- 481 phism of the Ostnu-PBAN gene pre-dates the diver- 482 gence of the Asian and European corn borer moths 483 approximately 1000000 years ago (Roelofs et al., 484 2002). 
When the synthetic Ostnu-PBAN was injected into decapitated females at a dose between 1.45 and 5.8 picomoles, it restored sex pheromone production to normal levels. Furthermore, there was a significant increase in pheromone production after injection of even 0.058 pmol synthetic Ostnu-PBAN. These results indicate that it is a hormonally active peptide. In mated females, pheromone production could be restored by injecting the synthetic Ostnu-PBAN, which suggests that the pheromone biosynthetic machinery remains intact and is fully capable of de novo synthesizing the pheromone blend. This result is consistent with our previous observation on the cabbage moth (Mamestra brassicae), where the injection of an 18-aa Mambr pheromonotropin reactivated pheromone production to normal levels after 5 days of mating (Köblös et al., 2015). Confirmatory findings were reported by Tabata et al. (2003) who reactivated sex pheromone biosynthesis in Os. scapulalis by a synthetic C-terminal amidated octapeptide of Helze-PBAN. The GC-MS analysis performed here indicates that, in line with Kárpáti et al. (2007), E11-14:Ac was produced at significantly higher levels in E-strain females than Z1114:Ac in Z-strain individuals. Roelofs et al. (1987) demonstrated that both E- and Z-strain ECB females have 14-carbon D11 unsaturated fatty acyl moieties with simi$\operatorname{lar} E / Z$ ratios of $\approx 70: 30$. This ratio corresponds closely to the difference in the production of the two main pheromone components between the two strains, but further studies are required to clarify any causal role.

Quantitative real-time PCR analysis showed that DH-PBAN precursor mRNA is present throughout the developmental stages from first-instar larvae to adults and in both sexes. Similar results have been reported in B. mori (Sato et al., 1994; Xu et al., 1995b), H. zea (Ma et al., 1998) and various other moths (reviewed by Rafaeli, 2009). Previous studies have demonstrated that, in addition to pheromone production, FXPRL-NH $\mathrm{N}_{2}$ peptides regulate other functions such as cuticular melanization in moth larvae (Matsumoto et al., 1990; Altstein et al., 1996; Raina et al., 2003), initiation of egg diapause in B. mori (Imai et al., 1991) and termination of pupal diapause in some heliothine moths (Sun et al., 2003; Xu \& Denlinger, 2003) (for review, see Denlinger, 2002; Jurenka, 2015). However, the physiological functions of DH and SGNPs in the ECB remain to be established. There is considerable evidence that diapause induction in the ECB is primarily a response to seasonal changes in day length and temperature (Mutchmor \& Beckel, 1958; Skopik \& Bowen, 1976; Takeda \& Skopik, 1985; Beck, 1989), and is mediated in part by the absence of the moulting hormone, ecdysone (Bean \& Beck, 1983; Gelman et al., 1992). There was an increase in the level of Ostnu-PBAN mRNA expression following adult eclosion that plateaued after 1 day and thereafter it was not affected by mating status. This is in 540 line with previous studies suggesting that postmating 541 inhibition of pheromone production may be associated 542 with cessation of PBAN release from the corpus cardia- 543 cum rather than reduced synthesis (Foster, 1993; 544 Jurenka \& Fabriás, 1993; Raina et al., 1994; Ando et al., 545 1996; Delisle et al., 2000). The process could be medi- 546 ated by hormonal and neural mechanisms as reviewed 547 extensively by Rafaeli (2011).

The benefits of identifying the Ostnu-PBAN precursor 549 are manifold. In physiological studies, synthetic Ostnu- 550 PBAN can be used to trigger in vivo and also in vitro 551 pheromone production, which may contribute to a better 552 understanding of the endogenous regulation of phero- 553 mone biosynthesis. It facilitates deciphering the func- 554 tional role of the other PBAN family neuropeptides (DH 555 and SGNPs) in the ECB, and can provide new insights 556 into practical means of manipulating insect homeostasis 557 and development. Furthermore, the ECB is an estab- 558 lished model organism in evolutionary biology and the 559 Ostnu-PBAN sequence information may shed more light 560 on the divergence and evolutionary origin of the genus 561 Ostrinia.

Experimental procedures

563 Insects

The E-strain laboratory colony of ECB was established from 565 two dozen larvae collected from maize plants near Žalec 566 $\left(46814^{\prime} 49.3^{\prime \prime} \mathrm{N}, 159^{\prime} 50.0^{\prime \prime} \mathrm{E}\right)$ in the Savinja valley, Slovenia, in 567 September 2010 (Rak Cizej et al., 2010). Likewise, the Z-strain 568 culture was established from larvae collected near Kéty 569 (46826'41.9' $\left.\mathrm{N}, 18831^{\prime} 26.8^{\prime \prime} \mathrm{E}\right)$, southern Hungary, in April 2010. 570 Larvae were reared on a semisynthetic diet (Nagy, 1970) under 571 a 18:6 h light/dark cycle at $25 \&$ and $50 \%$ relative humidity. 572 The resulting pupae were sexed and separated. In mating 573 experiments, newly emerged females ( $\sim 10$ individuals) were 574 placed with males ( $\sim 20$ individuals) in glass jars lined with plas- 575 tic bags for egg laying and kept for 3 days.

Furthermore, ECB larvae were collected from corn stalks in 577 Romhány $\left(4785^{\prime} 47.6^{\prime \prime} \mathrm{N}, 19815^{\prime} 45.8^{\prime \prime} \mathrm{E}\right)$ in northern Hungary 578 in December 2011 and 2012 (univoltine population) and in 579 Hódmezővásárhely $\left(46822^{\prime 37.6} 6^{\prime \prime} \mathrm{N}, 2088^{\prime 40.1}{ }^{\prime \prime} \mathrm{E}\right)$ in southern 580 Hungary in November 2011 (bivoltine population). In Sweden, 581 which is the northernmost extent of the species' range in 582 Europe, ECB larvae were captured in August 2011 from two 583 cornfields located at opposite coasts of Skane, the southern- 584 most Swedish province. Three and two ECB larvae were col- 585 lected from univoltine populations at Landskrona $\left(5583^{\prime} 0.4^{\prime \prime} \mathrm{N}, 586\right.$ $\left.1281^{\prime} 30.6^{\prime \prime} \mathrm{E}\right)$ and Ravlunda (55842'32.1"N, 1488'26.5"E), 587 respectively, as described by Lehmhus et al. (2012). Adult ECB 588 females and males were also collected from cornfields in 589 bivoltine areas: in the Savinja valley, Slovenia, in August 2013, 590 and at two sites in central Hungary near Martonvásár 591 $\left(47819^{\prime} 41.2^{\prime \prime} \mathrm{N}, \quad 18848^{\prime} 28.0^{\prime \prime} \mathrm{E}\right)$ and Bicske $\left(47828^{\prime} 33.9^{\prime \prime} \mathrm{N}, 592\right.$ $\left.18836^{\prime} 29.6^{\prime \prime} \mathrm{E}\right)$ during June and August 2015. In addition, 593 
multivoltine ECB (Zeren et al., 1988) males were captured by delta-type sticky traps baited with the Z-type lure near Adana $\left(37801^{\prime} 56.4^{\prime \prime} \mathrm{N}, 35822^{\prime} 50.7^{\prime \prime} \mathrm{E}\right)$ in southern Turkey in August 2014. Three genomic DNA samples extracted from individual males were selected from 24 samples for further analysis. Last but not least, field-collected adzuki bean borer moths (Os. scapulalis), a congener of ECB, were also included in this study. Adult Os. scapulalis moths (two males and two females) were captured in Matsudo $\left(35847^{\prime} 59^{\prime \prime} \mathrm{N}, 13984^{\prime} 0.8^{\prime \prime} \mathrm{E}\right)$, Japan, in 2008-2009, stored in ethanol and later provided to us for analysis.

\section{Gas chromatographic analysis of pheromone} components combined with electroantennographic detection

The pheromone components were monitored in ECB cultures using gas chromatography (GC) with electroantennographic detection (EAD) using antennae of adult male moths, as described by Kárpáti et al. (2007). Briefly, PGs were dissected from calling females during the second half of the scotophase and extracted in $n$-hexane. The extract was concentrated to 2 I I and analysed on a GC (6890 N, Agilent Technologies, Santa Clara, CA, USA) equipped with a flame ionization detector and a DB-Wax column $(30 \mathrm{~m} 30.32 \mathrm{~mm} 30.25 \mathrm{I} \mathrm{m}$ film thickness, J\&W Scientific, Folsom, CA, USA) using splitless mode injection, carrier gas helium and a temperature programme of $60 \AA \mathrm{C}$ for $1 \mathrm{~min}, 10 \mathrm{\&} / \mathrm{min}$ to $120 \propto \mathrm{C}, 5 \mathrm{C} / \mathrm{min}$ to $220 \mathrm{C}$, maintained for $40 \mathrm{~min}$. The EAD included a micromanipulator (MP15) and an IDAC 232 amplifier (Syntech, Kirchzarten, Germany). The reference compound was n-decyl acetate. The pheromone components were identified by retention times of synthetic E11- and $\mathrm{Z11}-14: \mathrm{Ac}$ and by the patterns of responses of male antennae from $E$ and $Z$ colonies.

\section{Gas chromatographic and mass spectrometric analysis} of pheromone components

Hexane extracts (in $20 \mathrm{~m}$ for $8 \mathrm{~min}$ ) of three PGs were transferred to conical vials and $5 \mathrm{~m}$ of $1 \mathrm{ng} / \mathrm{m} \mathrm{E}$ E,Z10-14:Ac (Pherobank BV) was added as an internal standard. GC-MS analysis was carried out on an Agilent 6890 GC equipped with a Rxi5Sil (30 m $30.25 \mathrm{~mm} 30.25 \mathrm{I}$ m film, Restek, Bellefonte, PA, USA) column and coupled to an Agilent 5973 mass selective detector operated in selected ion monitoring mode. Samples were injected in the splitless mode with helium used as a carrier gas at a flow rate of $2 \mathrm{~m} / \mathrm{min}$. The oven was programmed from 100 to $300 \mathrm{BC}$ at a rate of $20 \mathrm{BC} / \mathrm{min}$ after an initial delay of 1 min. All data were recorded and edited with CHEMSTATION software D.01.02.16 (Agilent Technologies), and quantification of E11- and Z11-14:Ac was performed using the internal standard mode.

\section{Strain typing of wild-caught moths}

For each individual used in this study, pheromone type was identified by genotyping for the pgFAR gene according to the method of Lassance et al. (2010). In a previous report, the $Z$ allele of pgFAR was identified in ECB larvae collected in Ravlunda and Landskrona, Sweden (Lehmhus et al., 2012). Briefly,
PCR amplifications were performed using the primers pgFAR-E 648 sense 5'-GGTTTGATATTGATTGAGGAGAG-3', pgFAR-E anti- 649 sense 5'-GGTTTGTTTGGTTGTAATTTATAGG-3', pgFAR-Z 650 sense $5^{\prime}$-CGACTAGAGTAGGTATGTAATATAG- $3^{\prime}$ and pgFAR-Z 651 antisense $5^{\prime}$-TTGAGTAAGCGTTTGTATGAAG-3' described by 652 Lassance et al. (2010). Genomic DNA or cDNA from total RNA 653 were used as the template as described in the next section. 654 Cycling conditions were $958 \mathrm{C}$ for $3 \mathrm{~min}, 30$ cycles at $95 \approx \mathrm{C}$ for 655 $30 \mathrm{~s}, 55 \& \mathrm{C}$ for $30 \mathrm{~s}$ and $72 \approx \mathrm{C}$ for $30 \mathrm{~s}$, followed by a final 656 extension of $72 \approx$ for 10 min with DreamTaq DNA Polymerase 657 (Thermo Fisher Scientific, Waltham, MA, USA). The 132-bp and 658 92-bp amplification products corresponding to pgFAR-E and 659 pgFAR-Z, respectively, were analysed by electrophoresis in 660 $1.5 \%$ agarose gels containing $0.5 \mathrm{I} \mathrm{g} / \mathrm{ml}$ ethidium bromide. The 661 specificity of the amplification was verified by sequencing of the 662 PCR products.

In the case of ECB collections from Hungary, we also used 664 GC-EAD or GC-MS methods to confirm the results. A number 665 of larvae from each collection site in Hungary were reared to 666 adulthood and the females were processed for pheromone anal- 667 ysis as indicated above.

Total RNA was isolated from five individual whole larvae col- 670 lected in Sweden and from pooled samples containing 15 brain- 671 SG complexes of 1-3-day-old virgin females obtained from 672 each of the E- and Z-strain laboratory colonies, or containing 673 15 heads of females collected in Bicske, central Hungary, in 674 June 2015. Tissue samples were homogenized in 900 I I QIAzol 675 lysis reagent (Qiagen, Valencia, CA, USA) using a microcentri- 676 fuge tube and pestle and RNA was extracted with an RNeasy 677 Plus Universal Mini kit (Qiagen) according to the manufacturer's 678 protocol. Isolated RNA samples were quantified by a NanoDrop 679 1000 spectrophotometer (Thermo Scientific).

Total RNA preparations were treated with DNase I (Life Tech- 681 nologies, Rockville, MD, USA) to remove residual genomic DNA, 682 and reverse transcribed to generate cDNA using SuperScript III 683 (Life Technologies) and random hexamer primers. Two degener- 684 ate oligonucleotide primers (sense 5'-GATGCCYTGAARTATTAYT 685 ACGA-3' and antisense 5'-RAGWCGAGGBKAGAAGTA-3'), cor- 686 responding to the conserved sequence motifs DALKYYY and 687 YFSPRL, respectively, were constructed based on the alignment 688 of lepidopteran DH-PBAN sequences available from GenBank. 689 PCR amplification of reverse transcribed brain-SG complex 690 mRNA was carried out under the following conditions: $98 \mathrm{\&}$ for 2691 min, 35 cycles at $98 \approx \mathrm{C}$ for $30 \mathrm{~s}, 53 \approx \mathrm{C}$ for $30 \mathrm{~s}$ and $72 \& \mathrm{C}$ for 692 $10 \mathrm{~s}$, followed by a final extension of $72 \approx \mathrm{C}$ for $10 \mathrm{~min}$ with Veloc- 693 ity DNA polymerase (Bioline). The amplified PCR products were 694 gel-purified with a High Pure PCR product purification kit (Roche, 695 Indianapolis, IN, USA), and ligated into the pJET1.2/blunt cloning 696 vector using a CloneJET PCR cloning kit (Thermo Scientific) 697 according to the manufacturer's protocol. The cloned PCR frag- 698 ments were sequenced at Macrogen Europe (Amsterdam, The 699 Netherlands) using pJET1.2 sequencing primers. BLAST 700 searches (http://www.ncbi.nlm.nih.gov/BLAST/) against the Gen- 701 Bank database revealed that the consensus sequence had 66- 702 $76 \%$ nucleotide similarity with other lepidopteran DH-PBAN 703 sequences. Sequence information of the cloned cDNA fragments 704 
705 was used to design gene-specific primers using PrIMER-BLAST 706 (http://www.ncbi.nlm.nih.gov/tools/primer-blast). Full-length cDNA 707 sequences were determined by $5^{\prime}$ - and $3^{\prime}$-RACE using the 708 SMARTer RACE cDNA amplification kit (Clontech, Mountain 709 View, CA, USA) according to the recommendations of the manu710 facturer. The two specific primers designed from the partial cDNA 711 fragment were 5'-CGATCAGCTCCCCTTCTACGAAAGC-3' for 3'712 RACE, and 5'-CATGAGAATCAGATGGCGTGACAGG-3' for $5^{\prime}$ 713 RACE. Amplification products were cloned into the pJET1.2/blunt 714 vector and two to 12 clones from each PCR product were 715 sequenced as above. RT-PCR amplifications were conducted 716 using primers designed based on the terminal segments of the 717 5'- and $3^{\prime}$-RACE products (sense $5^{\prime}$-GCTTTCGCCATAGACTC 718 AACCC-3' $3^{\prime}$ and antisense $5^{\prime}$-AATGAGGTATGAAGCGGCCAT-3'). 719 Thermocycler conditions consisted of $98 \&$ for $2 \mathrm{~min}, 32-35$ antisense $\quad 5^{\prime}$-ATCGTCCAAAACATTAACGTGTTAC-3'). These 763 primers were also used to amplify homologous regions from the 764 adzuki bean borer. Thermocycler conditions consisted of $98 \& 765$ for $2 \mathrm{~min}, 32-35$ cycles at $98 \mathrm{C}$ for $30 \mathrm{~s}, 60 \mathrm{C}$ for $30 \mathrm{~s}$ and 766 $72 \&$ for $1 \mathrm{~min}$, followed by a final extension of $72 \&$ for 10767 min with Velocity DNA polymerase.

768

The amplification products were isolated and sequenced as 769 described above to identify exon/intron boundaries. Nucleotide 770 sequences assembled from overlapping clones isolated from 771 Os. nubilalis and Os. scapulalis have been submitted to GenBank 772 under accession numbers KT588300, KU952096-KU952114 and 773 KX034792-KX034795. After conceptual translation, predictions of 774 signal peptide sequences and intron splice sites were performed 775 with the programs SignalP 4.1 and NetGene2, respectively, on 776 CBS Prediction Servers (http://www.cbs.dtu.dk/services/; Nielsen 777 et al., 1999; Petersen et al., 2011). Endoproteolytic cleavage sites 778 in the peptide precursor were predicted according to the rules 779 described by Veenstra (2000).

Tissue mRNA expression

781

Developmental and tissue-specific RT-PCRs were performed 782 using cDNA derived from total RNA extracted from laboratory 783 cultures of the ECB (eggs, first to fifth instars, pupae and 784 adults, as well as various organs and tissues of 3-day-old virgin 785 adult males and females: heads, brain-SG complexes, legs, 786 ovaries, fat bodies, pheromone glands, hairpencil-aedeagus 787 complexes and carcasses) using a RNeasy Plus Universal Mini 788 kit (Qiagen) and Extractme Total RNA kit (Blirt SA, DNA- 789 Gdańsk, Poland) according to the manufacturers' protocols. 790 Adults were considered 0 days old on the day of eclosion. 791 Brain-SG complexes were dissected from both sexes of pre- 792 emergence pupae, 0-, 1-, 2- and 3-day-old virgins, and 3-day 793 old mated adults as described above. After DNAse I treatment, 794 first-strand cDNA synthesis was performed with 1 I g total RNA 795 using a High-Capacity cDNA Reverse Transcription kit (Applied 796 Biosystems, Foster City, CA, USA) and random hexamer pri- 797 mers according to the manufacturer's instructions. 798

Real-time PCR analysis was performed to analyse the rela- 799 tive mRNA expression level in various tissues and developmen- 800 tal stages. The oligonucleotide primer pair designed to amplify 801 a 100-bp fragment spanning exons 3 and 4 (positions 264 to 802 363 relative to the translational start codon) of the Ostnu-PBAN 803 transcript consisted of: sense 5'-GGAGACCCGTGTGACAAA-3' 804 and antisense 5'-CGTGAATTCTACGTTCTCGAA-3'. Quantita- 805 tive PCR was performed on a CFX96 Touch Real-Time PCR 806 Detection System (Bio-Rad, Hercules, CA, USA) using Sensi- 807 FAST SYBR No-ROX kit (Bioline) in a 20 । I reaction volume 808 and running a standard programme $(95 \&$ for 2 min, 40 cycles 809 at $95 \&$ for $10 \mathrm{~s}, 60 \&$ for $10 \mathrm{~s}$ and $72 \&$ for $10 \mathrm{~s}$, followed by 810 a melt curve analysis to determine amplicon specificity using a 811 temperature range from 65 to $958 \mathrm{C}$ with increments of $0.58 \mathrm{C}$ ). 812 The amount of DH-PBAN mRNA was normalized to ribosomal 813 protein S3 (rpS3, GenBank AY513653 and DQ988989) mRNA 814 levels. The oligonucleotide primer pair used to amplify a 210-bp 815 fragment of rpS3 (from positions 178 to 378 ) consisted of: 816 sense 5'-CAGAGCGTACTGGGAGAGAAG-3' and antisense 5'- 817 GAACCTCAGCACACCATAGCA-3'. All reactions were per- 818 formed using three biological replicates in triplicate. In each 819 
run, water-only controls and non-reverse-transcribed RNA were used as negative controls. Quantification was performed using the standard curve method (Larionov et al., 2005) by serial dilutions of plasmids containing cloned fragments of DH-PBAN or rpS3 cDNA. All PCR efficiencies ranged between 100 and $103 \%$, with $r^{2} 50.99$ or higher. The products were purified with a High Pure PCR product purification kit (Roche) and sequenced (Macrogen Europe).

\section{Effect of synthetic Ostnu-PBAN}

Based on the deduced amino acid sequence of residues 128164, the 37-aa Ostnu-PBAN with an amidated C-terminus was custom synthesized by CASLO ApS (Technical University of Denmark, Lyngby, Denmark) with a purity $>99 \%$ (wt/wt) determined by high pressure liquid chromatography. Dose-response relationships of the pheromonotropic effect of the synthetic peptide were tested in decapitated E-strain females according to Raina \& Klun (1984). Two-day-old females were decapitated at the third hour of scotophase and $27 \mathrm{~h}$ later were injected with a dose series of synthetic Ostnu-PBAN $(0.058,0.29,0.58,1.45$, 2.9, 5.8 and $11.6 \mathrm{pmol}$ in $2 \mathrm{~m}$ distilled water) using a 10-। । Hamilton syringe. Each dose was replicated six times. Females injected with 2-m water served as controls. Ninety min after injection, pooled samples containing three PGs were extracted with $20 \mathrm{II} \mathrm{n}$-hexane for $8 \mathrm{~min}$ and subjected to GC-MS analysis.

The effect of the synthetic Ostnu-PBAN on pheromone production was monitored in both $\mathrm{E}$ - and Z-strain moths. Females were decapitated at the third hour of scotophase on days 0,1 and 2 of adult life and $27 \mathrm{~h}$ later were injected with $5.8 \mathrm{pmol}$ Ostnu-PBAN or water as described above. To assess the effect of mating, 3-day-old mated females were injected as above. Quantities of pheromone produced in decapitated or mated females were compared to those of 0-, 1-, 2- and 3-day-old intact virgins injected in a similar fashion. Pheromone extraction was performed 90 min after injection that occurred at the end of scotophase, when pheromone production peaked. The PGs were dissected, extracted with $\mathrm{n}$-hexane, and analysed for pheromone titre as described above.

\section{Statistical analysis}

All statistical analyses were performed using STATISTICA 6.1. software (StatSoft, Tulsa, OK, USA). Normality of distribution of the data was assessed by the Kolmogorov-Smirnov test. Differences between groups were evaluated by one-way analysis of variance followed by Duncan's multiple range test. Data are represented as mean 6 SEM for three or more independent measurements. A P-value of $<0.05$ was considered statistically significant.

\section{Acknowledgements}

We are grateful to M. Rak Cizej (Slovenian Institute of Hop Research and Brewing, Slovenia) for the E-strain ECB borers, Jörn Lehmhus (Julius Kühn Institute, Quedlinburg, Germany) and M. Bora Kaydan (Çukurova University, Adana, Turkey) for access to Z-strain ECB samples, and Yukio Ishikawa (Graduate School of Agri- 873 cultural and Life Sciences, University of Tokyo, Japan) 874 for Os. scapulalis samples. Thanks are due to Zoltán 875 Hegedűs for help in bioinformatic analysis, Gyöngyi Vaj- 876 dics for excellent technical assistance and two anony- 877 mous reviewers for helpful comments to improve this 878 manuscript. The research was supported by the Hungar- 879 ian Scientific Research Fund NKFIH (OTKA) K100421 880 and K104011, and the Marie Curie Career Integration 881 Grant (PCIG12-GA-2012-333980). Z.K. acknowledges 882 the support provided by the János Bolyai Research 883 Scholarship of the Hungarian Academy of Sciences. 884

\section{References}

Altstein, M., Gazit, Y., Ben-Aziz, O., Gabay, T., Marcus, R., Vogel, 886 Z. et al. (1996) Induction of cuticular melanization in Spodop- 887 tera littoralis larvae by PBAN/MRCH: development of a quan- 888 titative bioassay and structure function analysis. Arch Insect 889 Biochem Physiol 31: 355-370.

Altstein, M., Hariton, A. and Nachman, R. (2013) The FXPRLa- 891 mide (pyrokinin/PBAN) peptide family. In Handbook of Biologi- 892 cally Active Peptides (Kastin, A., ed.), pp. 255-266. Academic 893 Press, San Diego, CA.

Ando, T., Kasuga, K., Yajima, Y., Kataoka, H. and Suzuki, A. 895 (1996) Termination of sex pheromone production in mated 896 females of the silkworm moth. Arch Insect Biochem Physiol 897 31: 207-218.

898

Ando, T., Inomata, S.-I. and Yamamoto, M. (2004) Lepidopteran 899 sex pheromones. In The Chemistry of Pheromones and Other 900 Semiochemicals I, Topics in Current Chemistry, Vol. 239901 (Schulz, S., ed.), pp. 51-96. Springer, Berlin. 902

Anglade, P., Stockel, P. and IWGO Cooperators. (1984) Intraspe- 903 cific sex-pheromone variability in the European corn borer, 904 Ostrinia nubilalis Hbn. (Lepidoptera, Pyralidae). Agronomie 4: 905 183-187.

Bean, D.W. and Beck, S.D. (1983) Haemolymph ecdysteroid 907 titres in diapause and nondiapause larvae of the European 908 corn borer, Ostrinia nubilalis. J Insect Physiol 29: 687-693. 909

Beck, S.D. (1989) Factors influencing the intensity of larval dia- 910 pause in Ostrinia nubilalis. J Insect Physiol 35: 75-79.

Bjostad, L.B., Wolf, W.A. and Roelofs, W.L. (1987) Pheromone 912 biosynthesis in lepidopterans: desaturation and chain short- 913 ening. In Pheromone Biochemistry (Prestwich, G.D. and 914 Blomquist, G.J., eds), pp. 77-120. Academic Press, Orlando, 915 FL.

Bradbury, A.F. and Smyth, D.G. (1991) Peptide amidation. Trends 917 Biochem Sci 16: 112-115.

Caffrey, D.J. and Worthley, L.H. (1927) A Progress Report on the 919 Investigations of the European Corn Borer. Issue 1476 of 920 Department Bulletin. U.S. Department of Agriculture, Wash- 921 ington, DC.

Chang, J.C. and Ramasamy, S. (2014) Identification and expres- 923 sion analysis of diapause hormone and pheromone biosyn- 924 thesis activating neuropeptide (DH-PBAN) in the legume pod 925 borer, Maruca vitrata Fabricius. PLoS ONE 9: e84916. 926

Davis, M.T., Vakharia, V.N., Henry, J., Kempe, T.G. and Raina, 927 A.K. (1992) Molecular cloning of the pheromone biosynthesis- 928 activating neuropeptide in Helicoverpa zea. Proc Natl Acad 929 Sci USA 89: 142-146. 
931 Delisle, J., Picimbon, J.-F. and Simard, J. (2000) Regulation of pheromone inhibition in mated females of Choristoneura fumiferana and C. rosaceana. J Insect Physiol 46: 913-921.

Denlinger, D.L. (2002) Regulation of diapause. Annu Rev Entomol 47: 93-122.

Dillehay, B.L., Calvin, D.D., Roth, G.W., Hyde, J.A., Kuldau, G.A., Kratochvil, R.J. et al. (2005) Verification of a European corn borer (Lepidoptera: Crambidae) loss equation in the major corn production region of the northeastern United States. J Econ Entomol 98: 103-112.

Dopman, E.B., Pérez, L., Bogdanowicz, S.M. and Harrison, R.G. (2005) Consequences of reproductive barriers for genealogical discordance in the European corn borer. Proc Natl Acad Sci USA 102: 14706-14711.

Foster, S.P. (1993) Neural inactivation of sex pheromone production in mated lightbrown apple moths, Epiphyas postvittana (Walker). J Insect Physiol 39: 267-273.

Foster, S.P. (2004) Fatty acid and sex pheromone changes and the role of glandular lipids in the Z-strain of the European corn borer, Ostrinia nubilalis (Hübner). Arch Insect Biochem Physiol 56: 73-83.

Gäde, G. (1997) The explosion of structural information on insect neuropeptides. Prog Chem Org Nat Prod 71: 1-128.

Geiler, K.A. and Harrison, R.G. (2010) A D11 desaturase gene genealogy reveals two divergent allelic classes within the European corn borer (Ostrinia nubilalis). BMC Evol Biol 10: 112.

Gelman, D.B., Thyagaraja, B.S., Kelly, T.J., Masler, E.P., Bell, R.A. and Borkovec, A.B. (1992) Prothoracicotropic hormone levels in brains of the European corn borer, Ostrinia nubilalis: diapause vs the non-diapause state. J Insect Physiol 38: 383-395.

Imai, K., Konno, T., Nakazawa, Y., Komiya, T., Isobe, M., Koga, K. et al. (1991) Isolation and structure of diapause hormone of the silkworm, Bombyx mori. Proc Jpn Acad 67: 98-101.

Jing, T.Z., Wang, Z.Y., Qi, F.H. and Liu, K.Y. (2007) Molecular characterization of diapause hormone and pheromone biosynthesis activating neuropeptide from the black-back prominent moth, Clostera anastomosis (L.) (Lepidoptera, Notodontidae). Insect Biochem Mol Biol 37: 1262-1271.

Jurenka, R. (2015) The PRXamide neuropeptide signalling system: conserved in animals. In Advances in Insect Physiology, Vol. 49 (Jurenka, R., ed.), pp. 123-170. Academic Press, Oxford.

Jurenka, R. and Fabriás, G. (1993) Control of pheromone biosynthesis in mated redbanded leafroller moths. Arch Insect Biochem Physiol 137: 129-137.

Jurenka, R. and Nusawardani, T. (2011) The pyrokinin/pheromone biosynthesis-activating neuropeptide (PBAN) family of peptides and their receptors in Insecta: evolutionary trace indicates potential receptor ligand-binding domains. Insect Mol Biol 20: 323-334.

Kárpáti, Z., Molnár, B. and Szőcs, G. (2007) Pheromone titer and mating frequency of E-and Z-strains of the European corn borer, Ostrinia nubilalis: fluctuation during scotophase and age dependence. Acta Phytopathol Entomol Hung 42: 331341.

Kárpáti, Z., Fejes-Tóth, A., Csengele, B., Szőke, C., Bónis, P., Marton, L.C. et al. (2016) Pheromone-based monitoring of the European corn borer (Ostrinia nubilalis) in Hungary. Maydica 61: 1-7.

Kawano, T., Kataoka, H., Nagasawa, H., Isogai, A. and Suzuki, A. (1992) cDNA cloning and sequence determination of the pheromone biosynthesis activating neuropeptide of the silk- 992 worm, Bombyx mori. Biochem Biophys Res Commun 189: 993 221-226.

Keszthelyi, S. (2010) Flight dynamics analysis of the European 995 corn borer (Ostrinia nubilalis Hübner) populations in Hungary 996 from the second part of the twentieth century until the present. 997 Arch Phytopathol Plant Protect 43: 1286-1294.

Kitamura, A., Nagasawa, H., Kataoka, H., Inoue, T., Matsumoto, 999 S., Ando, T. et al. (1989) Amino acid sequence of pheromone-1000 biosynthesis-activating neuropeptide (PBAN) of the silkworm, 1001 Bombyx mori. Biochem Biophys Res Commun 163: 520-526. 1002

Klun, J.A. and Cooperators. (1975) Insect sex pheromones: intra-1003 specific pheromonal variability of Ostrinia nubilalis in North1004 America and Europe. Environ Entomol 4: 891-894. 1005

Klun, J.A., Chapman, O.L., Mattes, K.C., Wojtkowski, P.W.,1006 Beroza, M. and Sonnet, P.E. (1973) Insect sex pheromones:1007 minor amount of opposite geometrical isomer critical to attrac-1008 tion. Science 181: 661-663.

Köblös, G., Dankó, T., Sipos, K., Geiger, Á., Szlanka, T., Fodor, J. 1010 et al. (2015) The regulation of D11-desaturase gene expres-1011 sion in the pheromone gland of Mamestra brassicae (Lepi-1012 doptera; Noctuidae) during pheromonogenesis. Gen Comp1013 Endocrinol 221: 217-227.

Kochansky, J., Cardé, R.T., Liebherr, J. and Roelofs, W.L. (1975)1015 Sex pheromone of the European corn borer, Ostrinia nubilalis 1016 (Lepidoptera: Pyralidae), in New York. J Chem Ecol 1: 225-1017 231.

Kumar, S., Stecher, G. and Tamura, K. (2016) MEGA7: molecular1019 evolutionary genetics analysis version 7.0 for bigger datasets. 1020 Mol Biol Evol 33: 1870-1874.

Kuniyoshi, H., Nagasawa, H., Ando, T., Suzuki, A., Nachman,1022 R.J. and Holman, G.M. (1992) Cross-activity between phero-1023 mone biosynthesis activating neuropeptide (PBAN) and myo-1024 tropic pyrokinin insect peptides. Biosci Biotechnol Biochem 1025 56: 167-168.

Larionov, A., Krause, A. and Miller, W. (2005) A standard curve1027 based method for relative real time PCR data processing. 1028 BMC Bioinformatics 6: 62-77.

Lassance, J.-M. (2010) Journey in the Ostrinia world: from pest 1030 to model in chemical ecology. J Chem Ecol 36: 1155-1169. 1031

Lassance, J.-M., Groot, A.T., Liénard, M.A., Antony, B., 1032 Borgwardt, C., Andersson, F. et al. (2010) Allelic variation in a1033 fatty-acyl reductase gene causes divergence in moth sex1034 pheromones. Nature 466: 486-489.

Lassance, J.-M., Bogdanowicz, S.M., Wanner, K.W., Löfstedt, C.1036 and Harrison, R.G. (2011) Gene genealogies reveal differen-1037 tiation at sex pheromone olfactory receptor loci in pheromone 1038 strains of the European corn borer, Ostrinia nubilalis. Evolu-1039 tion 65: 1583-1593.

1040

Lehmhus, J., Cordsen-Nielsen, G., Söderlind, C., Szőcs, G., 1041 Lassance, J.-M., Fodor, J. et al. (2012) First records of the Z-1042 Race of European corn borer Ostrinia nubilalis (Hübner, 1043 1796) from Scandinavia. J Kulturpfl 64: 163-167. 1044

Lucas, K.J., Zhao, B., Liu, S.P. and Raikhel, A.S. (2015) Regula-1045 tion of physiological processes by microRNAs in insects. Curr 1046 Opin Insect Sci 11: 1-7.

Ma, P.W.K. and Roelofs, W.L. (1995a) Sites of synthesis and 1048 release of PBAN-like factor in the female European corn1049 borer, Ostrinia nubilalis. J Insect Physiol 41: 339-350. 1050

Ma, P.W.K. and Roelofs, W.L. (1995b) Anatomy of the neurose-1051 cretory cells in the cerebral and subesophageal ganglia of the 1052 
female European corn borer moth, Ostrinia nubilalis (Hübner) (Lepidoptera: Pyralidae). Int J Insect Morphol Embryol 24: 343-359.

Ma, P.W.K. and Roelofs, W.L. (1995c) Calcium involvement in the stimulation of sex pheromone production by PBAN in the European corn borer, Ostrinia nubilalis (Lepidoptera: Pyralidae). Insect Biochem Mol Biol 25: 467-473.

Ma, P.W.K., Knipple, D.C. and Roelofs, W.L. (1994) Structura organization of the Helicoverpa zea gene encoding the precursor protein for pheromone biosynthesis-activating neuropeptide and other neuropeptides. Proc Natl Acad Sci USA 91: 6506-6510.

Ma, P.W.K., Knipple, D.C. and Roelofs, W.L. (1998) Expression of a gene that encodes pheromone biosynthesis activating neuropeptide in the central nervous system of corn earworm, Helicoverpa zea. Insect Biochem Mol Biol 28: 373-385.

Martin, D.P., Murrell, B., Golden, M., Khoosal, A. and Muhire, B. (2015) RDP4: detection and analysis of recombination patterns in virus genomes. Virus Evol 1: vev003.

Masler, E.P., Raina, A.K., Wagner, R.M. and Kochansky, J.P. (1994) Isolation and identification of a pheromonotropic neuropeptide from the brain-suboesophageal ganglion complex of Lymantria dispar: a new member of the PBAN family. Insect Biochem Mol Biol 24: 829-836.

Matsumoto, S., Kitamura, A., Nagasawa, H., Kataoka, H., Orikasa, C., Mitsui, T. et al. (1990) Functional diversity of a neurohormone produced by the suboesophageal ganglion: molecular identity of melanization and reddish colouration hormone and pheromone biosynthesis activating neuropeptide. J Insect Physiol 36: 427-432.

Mészáros, Z. (1969) Phenological investigations on the Hungarian population of the European corn borer (Ostrinia nubilalis Hbn., Lepidoptera, Pyraustidae) in 1965-67. Acta Phytopathol Acad Sci Hung 4: 181-185.

Mutchmor, J.A. and Beckel, W.E. (1958) Importance of photoperiod and temperature in inducing diapause in the European corn borer, Pyrausta nubilalis (Hbn.). Nature 181: 204.

Nachman, R.J., Holman, G.M. and Cook, B.J. (1986) Active fragments and analogs of the insect neuropeptide leucopyrokinin: structure-function studies. Biochem Biophys Res Commun 137: 936-942.

Nagy, B. (1970) Rearing of the European corn borer (Ostrinia nubilalis Hbn.) on a simplified artificial diet. Acta Phytopatho Acad Sci Hung 5: 73-79.

Nielsen, H., Brunak, S. and von Heijne, G. (1999) Machine learning approaches for the prediction of signal peptides and other protein sorting signals. Protein Engng 12: 3-9.

Nusawardani, T., Kroemer, J.A., Choi, M.-Y. and Jurenka, R.A. (2013) Identification and characterization of the pyrokinin/ pheromone biosynthesis activating neuropeptide family of $\mathrm{G}$ protein-coupled receptors from Ostrinia nubilalis. Insect Mol Biol 22: 331-340.

O'Rourke, M.E., Sappington, T.W. and Fleischer, S.J. (2010) Managing resistance to $\mathrm{Bt}$ crops in a genetically variable insect herbivore, Ostrinia nubilalis. Ecol Appl 20: 1128-1236.

Ozawa, R. and Matsumoto, S. (1996) Intracellular signal transduction of PBAN action in the silkworm, Bombyx mori: involvement of acyl CoA reductase. Insect Biochem Mol Biol 26: 259-265.

Peña, A., Arn, H., Buser, H.-R., Rauscher, S., Bigler, F., Brunetti, R. et al. (1988) Sex pheromone of European corn borer,
Ostrinia nubilalis: polymorphism in various laboratory and field 1114 strains. J Chem Ecol 14: 1359-1366.

Percy-Cunningham, J.E. and McDonald, J.A. (1987) Biology and1116 ultrastructure of sex pheromone-producing glands. In Phero-1117 mone Biochemistry (Prestwich, G.D. and Blomquist, G.J., 1118 eds), pp. 27-75. Academic Press, Orlando, FL. 1119

Petersen, T.N., Brunak, S., von Heijne, G. and Nielsen, H. (2011) 1120 SignalP 4.0: discriminating signal peptides from transmem-1121 brane regions. Nat Methods 8: 785-786.

1122

Predel, R. and Nachman, R.J. (2006) The FXPRLamide (pyroki-1123 nin/PBAN) peptide family. In Handbook of Biologically Active1124 Peptides (Kastin, A.J., ed.), pp. 207-212. Academic Press, 1125 New York.

Rafaeli, A. (2011) Moth sex-pheromone production: biosynthetic 1127 pathways, regulatory physiology, inhibitory processes and dis-1128 ruption. In Moths: Types, Ecological Significance and Control1129 (Cauterruccio, L., ed.), pp. 1-29. Nova Science Publishers, 1130 New York.

Rafaeli, A. (2009) Pheromone biosynthesis activating neuropep-1132 tide (PBAN): regulatory role and mode of action. Gen Comp1133 Endocrinol 162: 69-78.

Raina, A and Kempe, T. (1990) A pentapeptide of the C-terminal 1135 sequence of PBAN with pheromonotropic activity. Insect Bio-1136 chem 20: 849-851.

Raina, A.K. and Klun, J.A. (1984) Brain factor control of sex pher-1138 omone production in the female corn earworm moth. Science 1139 225: 531-533.

Raina, A.K., Jaffe, H., Kempe, T.G., Keim, P., Blacher, R.W., 1141 Fales, H.M. et al. (1989) Identification of a neuropeptide hor-1142 mone that regulates pheromone production in female moths. 1143 Science 244: 796-798.

Raina, A.K., Kingan, T.G. and Giebultowicz, J.M. (1994) Mating-1145 induced loss of sex pheromone and sexual receptivity in 1146 insects with emphasis on Helicoverpa zea and Lymantria dis-1147 par. Arch Insect Biochem Physiol 25: 317-327. 1148

Raina, A.K., Kingan, T.G. and Kochansky, J.P. (2003) A pheromo-1149 notropic peptide of Helicoverpa zea, with melanizing activity, 1150 interaction with PBAN, and distribution of immunoreactivity. 1151 Arch Insect Biochem Physiol 53: 147-157.

Rak Cizej, M., Kárpáti, Z., Leskošek, G. and Radišek, S. (2010) 1153 Determination of the strain of European corn borer (Ostrinia nubi- 1154 lalis Hübner) in Savinja valley; preliminary monitoring of male1155 European corn borer with pheromone bait. Hop Bull 17: 65-73. 1156

Regier, J.C., Mitter, C., Solis, M., Hayden, J.E., Landry, B., Nuss, 1157 M. et al. (2012) A molecular phylogeny for the pyraloid moths 1158 (Lepidoptera: Pyraloidea) and its implications for higher-level1159 classification. Syst Entomol 37: 635-656.

1160

Roelofs, W.L. and Rooney, A.P. (2003) Molecular genetics and 1161 evolution of pheromone biosynthesis in Lepidoptera. Proc 1162 Natl Acad Sci USA 100: 9179-9184. 1163

Roelofs, W., Glover, T., Tang, X.H., Sreng, I., Robbins, P., 1164 Eckenrode, C. et al. (1987) Sex pheromone production and1165 perception in European corn borer moths is determined by 1166 both autosomal and sex-linked genes. Proc Natl Acad Sci1167 USA 84: 7585-7589.

Roelofs, W.L., Liu, W., Hao, G., Jiao, H., Rooney, A.P. and Linn, 1169 C.E. (2002) Evolution of moth sex pheromones via ancestral 1170 genes. Proc Natl Acad Sci USA 99: 13621-13626. 1171

Saitou, N. and Nei, M. (1987) The neighbour-joining method: a1172 new method for reconstructing phylogenetic trees. Mol Biol1173 Evol 4: 406-425. 
1175 Sato, Y., Ikeda, M. and Yamashita, O. (1994) Neurosecretory cells expressing the gene for common precursor for diapause hormone and pheromone biosynthesis-activating neuropeptide in the suboesophageal ganglion of the silkworm, Bombyx mori. Gen Comp Endocrinol 96: 27-36.

Skopik, S.D. and Bowen, M.F. (1976) Insect photoperiodism: an hourglass measures photoperiodic time in Ostrinia nubilalis. J Comp Physiol 111: 249-259.

Suang, S., Manaboon, M., Chantawannakul, P., Singtripop, T., Hiruma, K. and Kaneko, Y. (2015) Molecular cloning, developmental expression and tissue distribution of diapause hormone and pheromone biosynthesis activating neuropeptide in the bamboo borer Omphisa fuscidentalis. Physiol Entomol 40: 247-256.

Sun, J.-S., Zhang, T.-Y., Zhang, Q.-R. and Xu, W.-H. (2003) Effect of the brain and suboesophageal ganglion on pupal development in Helicoverpa armigera through regulation of FXPRLamide neuropeptides. Regul Pept 116: 163-171.

Tabata, J., Takanashi, T. and Ishikawa, Y. (2003) Pheromone analysis of wild female moths with a PBAN C-terminal peptide injection for an estimation of assortative mating in adzuki bean borer, Ostrinia scapulalis. J Chem Ecol 29: 2749-2759.

Takeda, M. and Skopik, S.D. (1985) Geographic variation in the circadian system controlling photoperiodism in Ostrinia nubilalis. J Comp Physiol A 156: 653-658.

Tamaki, Y. (1985) Sex pheromones. In Comprehensive Insect Physiology and Pharmacology, Vol. 9 (Kerkut, G.A. and Gilbert, L.I., eds.), pp. 145-191. Pergamon Press, Oxford.

Thompson, J.D., Gibson, T.J., Plewniak, F., Jeanmougin, F. and Higgins, D.G. (1997) The CLUSTAL_X windows interface: flexible strategies for multiple sequence alignment aided by quality analysis tools. Nucleic Acids Res 25: 4876-4882.

Veenstra, J.A. (2000) Mono- and dibasic proteolytic cleavage sites in insect neuroendocrine peptide precursors. Arch Insect Biochem Physiol 43: 49-63.
Xu, W.H. and Denlinger, D.L. (2003) Molecular characterization 1211 of prothoracicotropic hormone and diapause hormone in Heli-1212 othis virescens during diapause, and a new role for diapause 1213 hormone. Insect Mol Biol 12: 509-516.

Xu, W.-H., Sato, Y., Ikeda, M. and Yamashita, O. (1995a) Molecu-1215 lar characterization of the gene encoding the precursor pro-1216 tein of diapause hormone and pheromone biosynthesis 1217 activating neuropeptide (DH-PBAN) of the silkworm, Bombyx 1218 mori and its distribution in some insects. Biochim Biophys 1219 Acta 1261: 83-89.

Xu, W.-H., Sato, Y., Ikeda, M. and Yamashita, O. (1995b) Stage-1221 dependent and temperature-controlled expression of the 1222 gene encoding the precursor protein of diapause hormone1223 and pheromone biosynthesis activating neuropeptide in the 1224 silkworm, Bombyx mori. J Biol Chem 270: 3804-3808. 1225

Yasukochi, Y., Miura, N., Nakano, R., Sahara, K. and Ishikawa, Y.1226 (2011) Sex-linked pheromone receptor genes of the Euro-1227 pean corn borer, Ostrinia nubilalis, are in tandem arrays.1228 PLoS One 6: e18843.

Zeren, O., Güllü, M. and Şimşek, S. (1988) Some biological1230 investigations relating to the control of stalk borer (Sesamia1231 spp.) and European corn borer (Ostrinia nubilalis Hbn.) on 1232 corn in Mediterranean region. In Proceedings of the Sympo-1233 sium on Corn Borers and Control Measures (Kinaci, E., ed.), 1234 pp. 1-20. Adana, Turkey.

Zhang, T.Y., Sun, J.S., Liu, W.Y., Kang, L., Shen, J.L. and Xu, 1236 W.H. (2005) Structural characterization and transcriptional1237 regulation of the gene encoding diapause hormone and pher-1238 omone biosynthesis activating neuropeptide in the cotton boll-1239 worm, Helicoverpa armigera. Biochim Biophys Acta 1728:1240 44-52.

Zhu, J.W., Zhao, C.H., Lu, F., Bengtsson, M. and Löfstedt, C.1242 (1996) Reductase specificity and the ratio regulation of E/Z1243 isomers in pheromone biosynthesis of the European corn1244 borer, Ostrinia nubilalis (Lepidoptera: Pyralidae). Insect Bio-1245 chem Mol Biol 26: 171-176. 